\title{
Dynamic characteristics of a high-speed train gearbox in the vehicle-track coupled system excited by wheel defects
}

\author{
Zhiwei Wang ${ }^{\mathrm{a}}$, Paul Allen ${ }^{\mathrm{b}}$, Guiming Mei ${ }^{\mathrm{a}}$, Zhonghui Yin ${ }^{\mathrm{a}}$, Yao Cheng ${ }^{\mathrm{a}}$, Weihua Zhang ${ }^{\mathrm{a}}$ \\ aState Key Laboratory of Traction Power, Southwest Jiaotong University, Chengdu, Sichuan 610031 , \\ China; \\ ${ }^{\mathrm{b}}$ Institute of railway research, University of Huddersfield, Huddersfield, HD1 3DH, UK.
}

\begin{abstract}
To analyse and simulate the dynamic response of the gearbox in a vehicle-track system, a threedimensional vehicle-track coupled dynamics model for high-speed trains has been developed with comprehensive consideration of the transmission system. Using this dynamics model, the coupling effects between the gearbox housing and its connected components were analysed. Based on the dynamic results, the dynamic stress field of the gearbox housing can be obtained using the finite element methods. The model outputs were successfully validated through comparison with field test data. Following model validation, the dynamic stress and its distribution throughout the gearbox housing were further investigated under different excitations, including track irregularities, wheel polygonal wear and flatness. The results demonstrate a significant increase in the stress levels of the oil level window aperture and the bottom face of the housing, which coincides with the location of cracks that formed in the gearbox housing during frequent vehicle operation. Whilst a specific case has been studied here, the proposed dynamics model can be applied to related dynamic assessments, such as vibration or suspension parameter analyses, as well as stress analyses of any rail vehicle transmission system to guide the maintenance and design.
\end{abstract}

Keywords: Gearbox, vehicle-track, coupling effects, wheel polygonal wear, wheel flatness

\section{Introduction}

As typically configured in high-speed railway applications, the gearbox unit transmits the traction motor torque to the drive pinion via a flexible coupling. The torque is then transmitted to the wheelset by a meshed gear pair. Due to the nature of high-speed trains, relatively severe vibrations and typically high operating mileage, the gearbox tends to become the subject of wheel wear, which necessitates significant maintenance.

The transmission system is directly mounted to the vehicle via its suspension system and bearings and is hence subject to significant excitation from wheel-rail interactions [1, 2]. Wheel failures, such as polygonal wear and wheel flatness, can lead to severe impacts in the wheel-rail interface [3, 4]. Such defects aggravate the vehicle's dynamic performance resulting failures, such as gearbox housing cracking [2] and axle box bearing failure [4]. The abnormal dynamic performance of transmission systems significantly reduces the running safety and operational reliability of railway vehicles [5]. Consequently, further study of gear transmission systems' dynamic performance during train operation and the influences of wheel defects are needed.

The wheel flatness and polygonal wear phenomena frequently occur in railway vehicles, and significant research has focused on these particular problems [6, 7]. Wheel flatness is often caused by wheel slide during the vehicle braking process [8]. Although many studies have investigated wheel polygonal wear [9, 10], the mechanisms of its development are still not fully understood [11]. To address this ambiguity, this report focuses on the influences of wheel flatness and polygonal wear on the vehicle-track system through simulations and experiments [3,4,11-13]. Wheel flatness typically increases wheel-rail impact forces, causing high-frequency vibrations in the track system and wheelset, and so on. The classical Euler-Bernoulli beam model is suitable in low speed ranges; however, it overestimates the impact effects of high speeds [14]. The Timoshenko beam has widely been used in rail models with high-frequency characteristics due to the shear deformation and the

\footnotetext{
* Corresponding author. Email: 13880068468@163.com
} 
rotational inertia of the rail [15]. Numerous research studies have evaluated the effects of wheel flatness on different vehicle- track systems (rigid, flexible wheelset; Timoshenko beam rail, etc.) using various operating parameters [16-18]. However, the dynamic behaviour of transmission systems in high-speed trains considering wheel flatness has not yet been reported. In addition, previously explored impacts of polygonal wear on vehicle-track systems have mainly focused on wheel-rail interactions [19, 20], noise problems [21, 22] and track vibrations [23]. Recently, Wu et al. $[7,11]$ studied the effects of both wheel polygonal wear and flatness on the dynamic performance and stress responses of a wheelset via a vehicle-track coupled dynamics model in the SIMPACK environment. Meanwhile, Wang et al. [2, 24] assessed the dynamic performance of a transmission system excited by wheel polygonal wear, which strictly considered the torsional vibration of the gear pair.

In the present body of published literature, only a few studies have investigated the dynamic performance of gear transmission systems in the vibration environment of a vehicle-track coupled dynamic system. Fortunately, the dynamic performance of gear systems [25-28] has been widely reported. Recently, Chen [29] investigated the dynamic performance of a locomotive in the traction/braking process via a vertical locomotive-track coupled dynamics model. Furthermore, Huang [1] studied the effects of gear transmission systems on the vibration of vehicle systems, whereas Wang et al. [30-32] investigated the dynamic interactions of the axle box bearing in the vehicle-track coupled system. These studies indicate that the coupling effects between the transmission system and the vehicle-track system are intense and cannot be neglected. However, the helical gear pair was also simplified as a pure torsional vibration model.

Overall, few studies have focused on the dynamic interactions between the transmission system and the vehicle-track system, especially under the conditions of wheel polygonal wear and flatness. Hence, the effects of the most common wheel defects on the dynamic behaviours of the gearbox housing require more detailed attention. The main objective of this paper is to investigate the gearbox housing dynamic characteristics in the vehicle-track coupled vibration system under the effects of wheel polygonal wear and flatness.

In the proposed model, the transmission system is comprehensively considered, by including not only modes of torsional vibration but also lateral and vertical vibrations caused by complicated excitations from the traction motor, wheel-rail interface and internal gear meshing process (timevarying mesh stiffness, gear errors). Based on our model, the dynamic stress analysis frame of the gearbox housing is established, enabling investigation of the dynamic stress fields of the gearbox housing during operation. To validate the simulation models, experimental field tests were performed on the Beijing-Shanghai high-speed railway line. The dynamic responses of the gearbox housing were then investigated in the vehicle-track coupled system whilst excited by (a) wheel polygonal wear with different wear amplitudes, (b) various harmonic orders of wheel polygonal wear and (c) different lengths of wheel flat to assess dynamic performance. By assessing these factors, the design, maintenance and condition monitoring of the whole system may be meaningfully improved.

\section{Vehicle-track coupled dynamics model}

The three-dimensional vehicle-track coupled dynamics model of a high-speed train is comprised of three subsystems: a vehicle subsystem that includes the traction transmission system, a slab-track subsystem and a wheel-rail subsystem. Each subsystem is introduced in detail below.

\subsection{Vehicle subsystem comprising traction transmission system}

A vehicle-track coupled dynamics model is developed by integrating the traditional vehicle- track coupled dynamics model [33] with newly added traction transmission systems, as displayed in Figure 1[34]. It can be seen that the carbody connects with the two bogies using the secondary suspension systems. The dynamic interactions between the bogie frames and wheelsets are achieved by the primary suspension systems. The traction motor is flexibly suspended on the bogie frame, as exhibited in in Figure 1 (b). The gearbox housing is mounted between the bogie frame and wheelset via rubber springs and bearings, respectively, which can be observed in Figure 2. The connections between the vehicle components are modelled as linear springs and damper elements. The nonlinear 
properties of the bumpstops, lateral and yaw dampers are also considered in the proposed dynamics model.

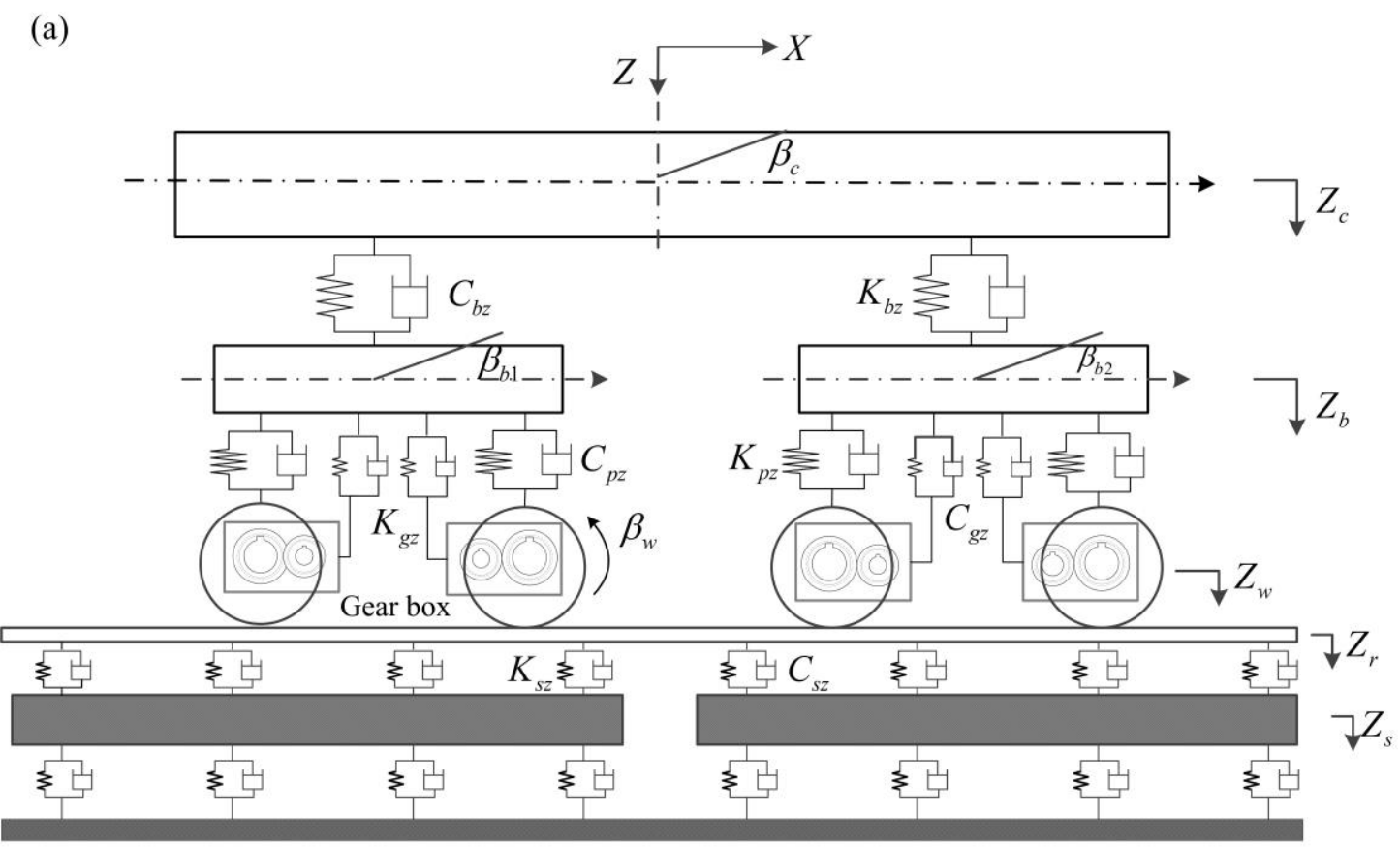

(b)

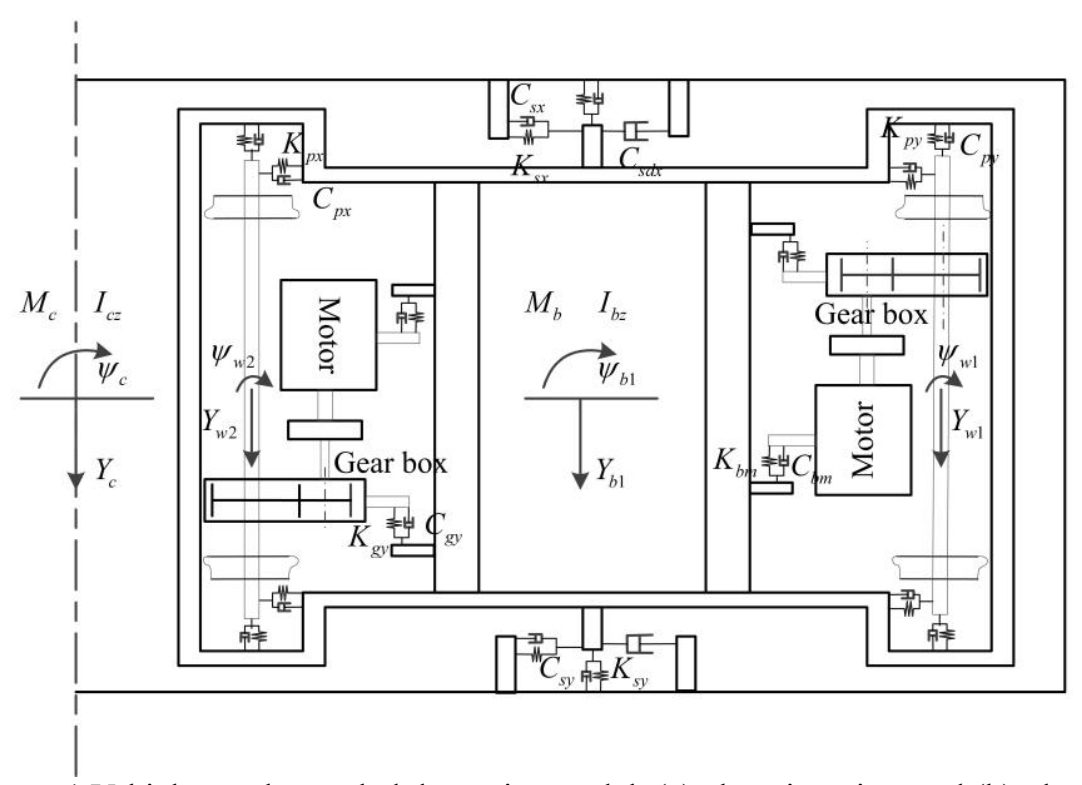

Figure 1 Vehicle-track coupled dynamics model: (a) elevation view and (b) planform.

Figure 2 shows the gear transmission systems of high-speed train, which is mounted between the wheelset and bogie frame via bearings and elastic suspensions, respectively. The gearbox housing moves and rotates with the axle of the wheelset in the model. Moreover, the lateral and vertical vibrations of the gearbox housing relative to the bogie frame are also considered. The gear wheel and wheelset axle are connected under an interference fit, and the pinion is supported by the gearbox housing. Therefore, the mesh forces acting on the pinion will be transmitted to the gearbox housing; hence, the model considers the internal dynamic forces and their coupling effects on the gearbox housing. As for external excitations, torque from the traction motor is transmitted by the gear mesh forces, and the excitations from the wheel-rail and bogie are directly transmitted to the gearbox housing via the wheelset and elastic suspension elements. Thus, the proposed dynamics model can fully represent the dynamic characteristics and mechanisms of a typical high-speed train's transmission system.

A dynamics model of a single-stage helical gear pair is illustrated in Figure 2 (c). The gear pair is modelled using rigid discs with their respective mass and moment of inertia. The gear wheel rotates 
with the axle of the wheelset and moves with the wheelset. Hence, only the motion equations of the pinion are given here, and the other equations of the vehicle system are not repeated here, as they have been introduced in a previous work [30]. The dynamic equations of the pinion can be obtained as:

$$
\left\{\begin{array}{l}
M_{p} \ddot{X}_{p i}+F_{p x i 1}+F_{p x i 2}+F_{m x i}=0 \\
M_{p} \ddot{Y}_{p i}+F_{p y i}+F_{m y i}=0 \\
M_{p} \ddot{Z}_{p i}+F_{p z i 1}+F_{p z i 2}+F_{m z i}=0 \\
I_{p x} \ddot{\phi}_{p i}-(-1)^{i} F_{p z i 1} l+(-1)^{i} F_{p z i 2} l=0 \\
I_{p y} \ddot{\beta}_{p i}+F_{m z i} R_{p}-T_{p i}=0 \\
I_{p z} \ddot{\psi}_{p i}-(-1)^{i} F_{p x i 1} l+(-1)^{i} F_{p z i 2} l+F_{m y i} R_{p}=0
\end{array} \quad(i=1,2,3,4)\right.
$$

where $M_{p}$ is the mass of pinion; $I_{p x}, I_{p y}$ and $I_{p z}$ are the moments of inertia of the pinion around the $\mathrm{X}, \mathrm{Y}$ and $\mathrm{Z}$ axis, respectively; $l$ is the half of the transverse distance between the centres of the bearings of the pinion; $T_{\mathrm{p}}$ is the torque from the traction motor; and $F_{p x}, F_{p y}$ and $F_{p z}$ are the dynamic forces between the pinion and gearbox housing in the longitudinal, lateral and vertical directions, respectively.

(a)

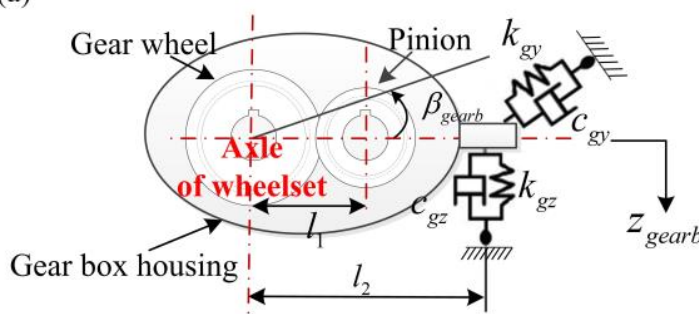

(b)

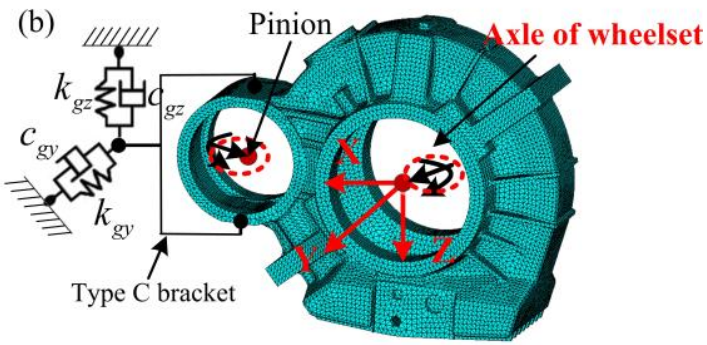

(c)

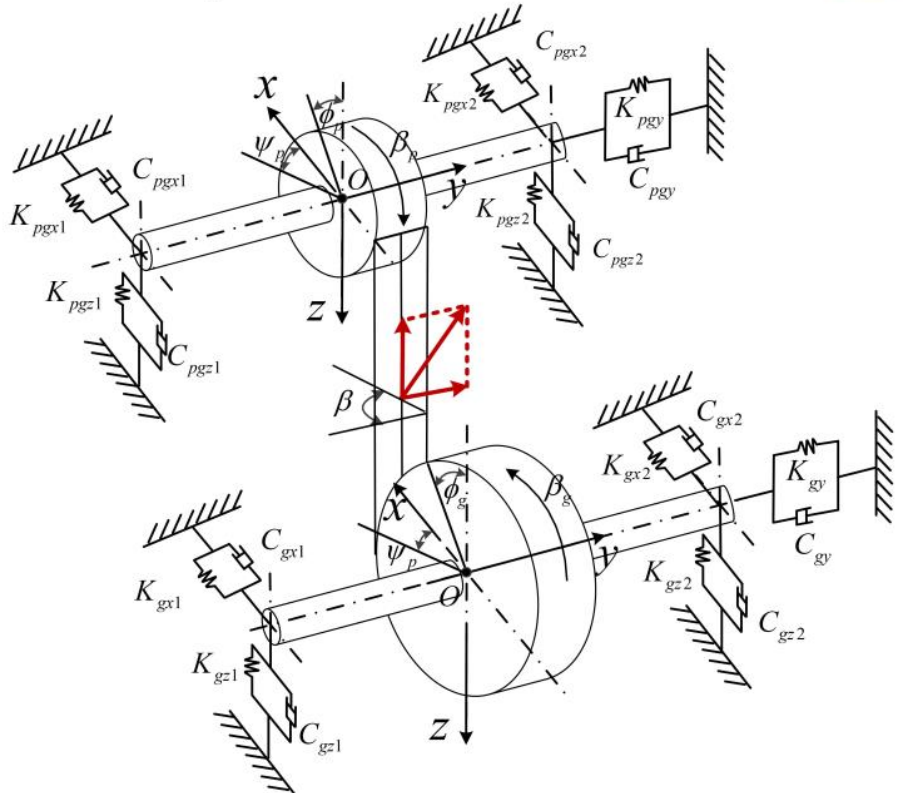

Figure 2 Gear transmissions system of high-speed train. (a) Gearbox, (b) the connections between the gearbox housing and vehicle, and (c) dynamics model of helical gear pair.

The dynamic gear mesh forces in the longitudinal $\left(F_{m x}\right)$, lateral $\left(F_{m y}\right)$ and vertical $\left(F_{m z}\right)$ directions can be calculated by Eqs. (2)- (4), respectively.

The gear mesh forces in the longitudinal direction:

$$
\begin{aligned}
F_{m x i}= & K_{m} \sin \alpha_{n}\left[X_{p i}-\psi_{w i} l_{g w} \tan \alpha_{t}\left(Z_{p i}-Z_{w i}+\beta_{p i} R_{p}+\beta_{w i} R-(-1)^{i} \phi_{w i} d_{g w}\right)\right] \\
& +C_{m} \sin \alpha_{n}\left[\dot{X}_{p i}-\dot{\psi}_{w i} l_{g w} \tan \alpha_{t}\left(\dot{Z}_{p i}-\dot{Z}_{w i}+\dot{\beta}_{p i} R_{p}+\dot{\beta}_{w i} R-(-1)^{i} \dot{\phi}_{w i} d_{g w}\right)\right] \quad(i=1,2,3,4)
\end{aligned}
$$

The gear mesh forces in the lateral direction: 


$$
\begin{aligned}
F_{m y i}= & K_{m} \sin \alpha_{n}\left[Y_{p i}-Y_{w i}-\tan \beta\left(Z_{p i}-Z_{w i}+\beta_{p i} R_{p}+\beta_{w i} R_{g}-(-1)^{i} \phi_{w i} d_{g w}\right)\right] \\
& +C_{m} \sin \alpha_{n}\left[\dot{X}_{p i}-\dot{Y}_{w i}-\tan \beta\left(\dot{Z}_{p i}-\dot{Z}_{w i}+\dot{\beta}_{p i} R_{p}+\dot{\beta}_{w i} R_{g}-(-1)^{i} \dot{\phi}_{w i} d_{g w}\right)\right] \quad(i=1,2,3,4)
\end{aligned}
$$

The gear mesh forces in the vertical direction:

$$
\begin{aligned}
F_{m z i}= & K_{m} \cos \alpha_{n} \sin \beta\left[Z_{p i}-Z_{w i}+\beta_{p i} R_{p}+\beta_{w i} R_{g}-(-1)^{i} \phi_{w i} d_{g w}\right] \\
& +C_{m} \cos \alpha_{n} \sin \beta\left[\dot{Z}_{p i}-\dot{Z}_{w i}+\dot{\beta}_{p i} R_{p}+\dot{\beta}_{w i} R_{g}-(-1)^{i} \dot{\phi}_{w i} d_{g w}\right] \quad(i=1,2,3,4)
\end{aligned}
$$

In Eqs. (2)-(4), $K_{m}$ and $C_{m}$ are the mesh stiffness and damping, respectively; $\alpha_{t}$ and $\alpha_{n}$ are the gear transverse and normal pressure angle, respectively; $d_{g w}$ is the lateral distance between the centres of the gear wheel and wheelset; $R_{p}$ and $R_{g}$ are the base circle radii of the pinion and gear wheel, respectively; and $\beta$ is the helical angle of the gear. Then, the spring-damping dynamic forces between the pinion and gearbox housing in the lateral and vertical direction can be calculated by Eqs. (5)-(6), respectively.

The dynamic forces between the pinion and gearbox housing in the lateral direction:

$$
F_{p g y j}=K_{p g y j}\left(Y_{p i}-Y_{g h i}\right)+C_{p g y j}\left(\dot{Y}_{p i}-\dot{Y}_{y h i}\right) \quad(i=1,2,3,4 ; j=1,2)
$$

The dynamic forces between the pinion and gearbox housing in the vertical direction:

$$
\begin{aligned}
F_{p g z i j}= & K_{p g z j}\left[Z_{p i}-(-1)^{j} \phi_{p i} l-Z_{g h i}-(-1)^{j} \beta_{g h i} l_{p}\right] \\
& C_{p g z j}\left[\dot{Z}_{p i}-(-1)^{j} \dot{\phi}_{p i} l-\dot{Z}_{g h i}-(-1)^{j} \dot{\beta}_{g h i} l_{p}\right] \quad(i=1,2,3,4 ; j=1,2)
\end{aligned}
$$

In Eqs. (5)-(6), $K_{p g y}\left(C_{p g y}\right)$ and $K_{p g z}\left(C_{p g z}\right)$ are the pinion support stiffness (damping) coefficients in the lateral and vertical directions, respectively; $l_{p}$ is the longitudinal distance between the centres of the pinion and gear wheel.

The same finite element model (FEM) of the gear pair employed in [30] is adopted in this study to perform the time-varying mesh stiffness. According to the previous analysis, the proposed vehicle dynamics submodel comprises 19 rigid bodies with 79 degrees of freedom (DOF). The DOFs and symbols of the vehicle components are given in Table 1. Generally, the vehicle motion equations can be described in the form of second-order differential equations as:

$$
\mathbf{M}_{\mathrm{v}} \ddot{\mathbf{X}}_{\mathrm{v}}+\mathbf{C}_{\mathrm{v}} \dot{\mathbf{X}}_{\mathrm{v}}+\mathbf{K}_{\mathrm{v}} \mathbf{X}_{\mathrm{v}}=\mathbf{F}_{\mathrm{WR}}+\mathbf{F}_{\text {ext }}
$$

where the $\mathbf{X}_{v}, \dot{\mathbf{X}}_{v}$ and $\ddot{\mathbf{X}}_{v}$ are the vectors of displacements, velocities and accelerations of the vehicle system, respectively; $\mathbf{M}_{\mathrm{v}}, \mathbf{C}_{\mathrm{v}}$ and $\mathbf{K}_{\mathrm{v}}$ are the mass matrix, damping matrix and stiffness matrix of the vehicle systems, respectively; $\mathbf{F}_{\mathrm{WR}}$ is the nonlinear wheel-rail contact forces vectors; and $\mathbf{F}_{\text {ext }}$ is the external forces, such as the traction forces and vehicle operation resistance forces. The details of the system equations and their derivation, together with the parameters used, are omitted here, as they are similar to the equations presented in [30].

\begin{tabular}{llllll}
\multicolumn{7}{c}{ Table 1 DOFs of vehicle system } \\
\hline Vehicle component & Lateral & Vertical & Roll & Yaw & Pitch \\
\hline Car body & $\mathrm{Y}_{\mathrm{c}}$ & $Z_{\mathrm{c}}$ & $\phi_{\mathrm{c}}$ & $\psi_{\mathrm{c}}$ & $\beta_{\mathrm{c}}$ \\
Bogie frame $(i=1,2)$ & $Y_{\mathrm{b} i}$ & $Z_{\mathrm{b} i}$ & $\phi_{\mathrm{b} i}$ & $\psi_{\mathrm{b} i}$ & $\beta_{\mathrm{b} i}$ \\
Motor $(i=1-4)$ & $Y_{\mathrm{m} i}$ & $Z_{\mathrm{m} i}$ & - & - & $\beta_{\mathrm{m} i}$ \\
Gearbox housing $(i=1-4)$ & $Y_{\mathrm{gh} i}$ & $Z_{\mathrm{gh} i}$ & - & - & $\beta_{\mathrm{gh} i}$ \\
Pinion $(i=1-4)$ & $Y_{\mathrm{p} i}$ & $Z_{\mathrm{p} i}$ & $\phi_{p i}$ & $\psi_{p i}$ & $\beta_{\mathrm{p} i}$ \\
Wheelset $(i=1-4)$ & $Y_{\mathrm{w} i}$ & $Z_{\mathrm{w} i}$ & $\phi_{\mathrm{w} i}$ & $\psi_{\mathrm{w} i}$ & $\beta_{\mathrm{w} i}$ \\
\hline
\end{tabular}

\subsection{Slab-track subsystem}

In this investigation, a slab-track structure widely used in China is employed, which comprises the rail, rail pads, slabs and subgrade, as illustrated in Figure 1. The rail is modelled as the Timoshenko beam which is supported by slabs. Combined with the modal superposition method, the governing 
equations of the rails are described using ordinary differential equations and are given below [ 35 , 36]. The lateral vibration equation can be written as:

$$
\ddot{q}_{y k}+\frac{\kappa_{y} G A}{m}\left(\frac{k \pi}{l}\right)^{2} q_{y k}(t)-\kappa_{y} G A \frac{k \pi}{l} \sqrt{\frac{1}{m \rho I_{y}}} \omega_{y k}(t)=-\sum_{i=1}^{N_{s}} F_{s y i} Y_{k}\left(x_{s i}\right)+\sum_{j=1}^{N_{w}} F_{w y j} Y_{k}\left(x_{w j}\right)
$$

where $q_{y k}$ is the generalised coordinates performing the rail lateral deformation; $m$ is the rail mass per unit length; $\rho$ is the rail density; $G$ and $E$ are the shear modulus and Young's modulus, respectively; $A$ is the cross section area of the rail; $l$ is the calculation length of the rail; $F_{s y i}$ and $F_{w y j}$ are the lateral forces acting on the rail from the slab and wheelset, respectively; $x_{s i}$ and $x_{w j}$ are the longitudinal positions of the slab (i) and wheelset (j), respectively; and $N_{w}$ and $N_{s}$ are the number of wheels and slabs in the model, respectively. The generalised coordinates of the rail deflection curve with respect to the lateral direction, $\omega_{y k}$, can be obtained by:

$$
\ddot{\omega}_{y k}(t)+\left[\frac{\kappa_{y} G A}{\rho I_{z}}+\frac{E I_{Z}}{\rho I_{z}}\left(\frac{k \pi}{l}\right)^{2}\right] \omega_{y k}(t)-\kappa_{y} G A \frac{k \pi}{l} \sqrt{\frac{1}{m \rho I_{z}}} q_{y k}(t)=0
$$

where $I_{z}$ is the second moments of the rail around the $\mathrm{Z}$ axis. The vertical vibration equation is obtained by:

$$
\ddot{q}_{z k}(t)+\frac{\kappa_{z} G A}{m}\left(\frac{k \pi}{l}\right)^{2} q_{z k}(t)-\kappa_{z} G A \frac{k \pi}{l} \sqrt{\frac{1}{m \rho I_{y}}} \omega_{z k}(t)=-\sum_{i=1}^{N_{s}} F_{s z i} Z_{k}\left(x_{s i}\right)+\sum_{j=1}^{N_{w}} F_{w z j} Z_{k}\left(x_{w j}\right)
$$

where $q_{z k}$ is the generalised coordinates performing the vertical rail deformation and $F_{s z i}$ and $F_{w z j}$ are the vertical forces acting on the rail from the slab and wheelset, respectively. The generalised coordinates of the rail deflection curve with respect to the vertical direction, $\omega_{z k}$ is then obtained by:

$$
\ddot{\omega}_{z k}(t)+\left[\frac{\kappa_{z} G A}{\rho I_{y}}+\frac{E I_{y}}{\rho I_{y}}\left(\frac{k \pi}{l}\right)^{2}\right] \omega_{z k}(t)-\kappa_{z} G A \frac{k \pi}{l} \sqrt{\frac{1}{m \rho I_{y}}} q_{z k}(t)=0
$$

where $I_{y}$ is the second moments of the rail around the $\mathrm{Y}$ axis. The torsional vibration equation is obtained by:

$$
\ddot{q}_{T k}(t)+\frac{G K}{\rho I_{0}}\left(\frac{k \pi}{l}\right) q_{T k(t)}=-\sum_{i=1}^{N_{s}} M_{s z i}(t) T_{k}\left(x_{s i}\right)+\sum_{j=1}^{N_{w}} M_{w z i} T_{k}\left(x_{w i}\right)
$$

where $q_{\mathrm{T} k}$ is the generalised coordinates performing the rotational rail deformation, and $M_{s z i}$ and $M_{w i i}$ are the moments acting on the rail from the slab and wheelset, respectively.

The elastic rectangular plates are used to model the slabs, which are supported on a viscoelastic foundation. The vertical flexible deformation of the slab is considered, whereas the slab in the lateral direction is regarded as a rigid body [33]. In general, the equations of the track subsystem can be expressed as:

$$
\mathbf{M}_{\mathrm{T}} \ddot{\mathbf{X}}_{\mathrm{T}}+\mathbf{C}_{\mathrm{T}} \dot{\mathbf{X}}_{\mathrm{T}}+\mathbf{K}_{\mathrm{T}} \mathbf{X}_{\mathrm{T}}=\mathbf{F}_{\mathrm{WR}}
$$

where $\mathbf{M}_{\mathrm{T}}, \mathbf{C}_{\mathrm{T}}$ and $\mathbf{K}_{\mathrm{T}}$ are the mass, damping and stiffness matrices of the slab-track subsystem, respectively; $\mathbf{X}_{\mathrm{T}}$ is the generalised coordinates of the slab-track subsystem; and $\mathbf{F}_{\mathrm{WR}}$ is the nonlinear contact forces vectors from the wheel-rail interface.

\subsection{Wheel-rail Subsystem}

The wheel-rail subsystem is the key element coupling the vehicle subsystem and the slab-track subsystem. The method for the calculation of the wheel/rail contact points and the geometric contact parameters in literature [37] is adopted in this investigation. Based on the contact parameters, the wheel/rail forces can be further calculated. The nonlinear dynamic forces between the wheel and rail are complex, which comprises the normal contact forces and tangential creep forces. The normal wheel-rail forces are calculated based on the nonlinear Hertzian elastic contact theory [38]:

$$
P(t)= \begin{cases}{\left[\frac{1}{G} \delta Z(t)\right]^{3 / 2}} & , \delta Z(t)>0 \\ 0 & , \delta Z(t)<0\end{cases}
$$


where $P(t)$ represents the normal wheel-rail force, $G$ represents the wheel-rail Hertzian contact constant, and $\delta Z(t)$ represents the elastic compression deformation of the wheel-rail contact in the normal direction. As for the wheel-rail creep forces, the Shen-Hedrick-Elkins model [39] is used to make modifications according to Kalker's linear creep theory [40], which is limited in small creepages. In the proposed vehicle-track coupled dynamics model, the CN60 rail profile and S1002CN wheel profile are adopted.

\subsection{Wheel polygonal wear and flat model}

Wheel polygonal wear frequently results from operation of high-speed trains, which causes violent wheel-rail interactions. An idealised polygonal wheel shape is adopted in the investigations. The harmonic function is applied to simulate the wheel polygonal wear, which is given as follows:

$$
r(\beta)=R-A \sin \left(N \beta+\beta_{0}\right)
$$

where $A$ represents the amplitude of polygonal wear; $N$ represents the polygonal wear order; $\beta$ and $\beta_{0}$ are the wheel rotation angle and initial phase angle, respectively; and $R$ is the nominal rolling radius of wheel.

Wheel flat is also a common defect for railway vehicle wheelsets, which can significantly contribute to the vibrations of the vehicle and track system due to the enhanced wheel-rail dynamic loads. The wheel flat model employed in [41] is adopted here, which is given as follows:

$$
r=\frac{1}{2} D_{f}\left[1-\cos \left(2 \pi x / L_{f}\right)\right], \quad D_{f}=F_{f}^{2} /(16 R)
$$

where $D_{f}$ represents the flat depth, $L_{f}$ is the length of the flat, and $R$ is the nominal wheel radius. A maximum length of $60 \mathrm{~mm}$ is adopted based on relevant literature [7].

\subsection{Flexible gearbox housing model}

The FEM is widely used to calculate the dynamic responses of engineering structures [42]. Hence, to obtain the dynamic characteristics of the gearbox housing during train operation, stress analysis in the vehicle-track coupled dynamics system was implemented using FEM under various conditions. The governing equations of the gearbox housing FEM can be described as [43]:

$$
\mathbf{M}_{\mathrm{gh}} \ddot{\mathbf{X}}_{\mathrm{gh}}(\mathrm{t})+\mathbf{C}_{\mathrm{gh}} \dot{\mathbf{X}}_{\mathrm{gh}}(\mathrm{t})+\mathbf{K}_{\mathrm{gh}} \mathbf{X}_{\mathrm{gh}}(\mathrm{t})=\mathbf{Q}_{\mathrm{gh}}(\mathrm{t})
$$

Where $\mathbf{M}_{\mathrm{gh}}, \mathbf{C}_{\mathrm{gh}}$ and $\mathbf{K}_{\mathrm{gh}}$ are the mass matrix, damping matrix and the stiffness matrix, respectively, and $\mathbf{Q}_{\mathrm{gh}}(\mathrm{t})$ is the node loads vector.

The dynamic stress analysis procedure of the gearbox housing comprises three parts, namely, the excitations, the vehicle-track coupled dynamics model and the dynamic stress analysis (Figure 3 ). Within the vehicle-track coupled systems, the gearbox housing is principally excited through wheel-rail interactions and gear meshing vibrations. Hence, these excitations are considered in the stress analysis process, as exhibited in Figure 3 (a). Besides, the wheel flat and wheel polygonal wear could also be considered. And then, the dynamic interactions between the transmission systems and the other vehicle components can be obtained by the coupled dynamics model as presented in Figure 3 (b), which are used as the inputs for the stress analysis of gearbox housing based on FEM. As can be observed in Figure 3 (c), the finite element model of the gearbox housing is developed in ANSYS. In the dynamic stress simulations, the dynamic interactions between the gearbox housing and its related components are considered, such as the dynamic vertical and lateral forces between the gearbox housing and bogie frame; the dynamic forces acting on the gearbox housing from the pinion, and the dynamic displacement in the center of the pinion bearing housing itself. In addition, the coupling constraints of the pinion and gearwheel bearing housings are considered. All DOFs of the gearwheel bearing housing are restrained, with the exception of rotation around the axle, as shown in Figure 3 (c). 
(a) Excitations

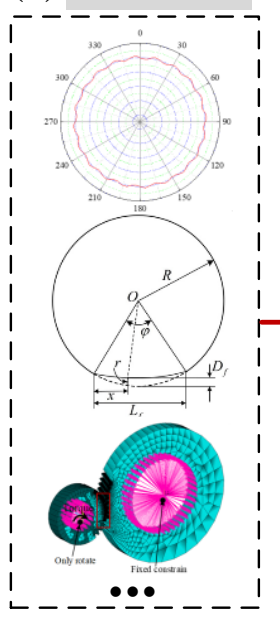

(c) (b) The novel spatial vehicle-track coupled dynamics model

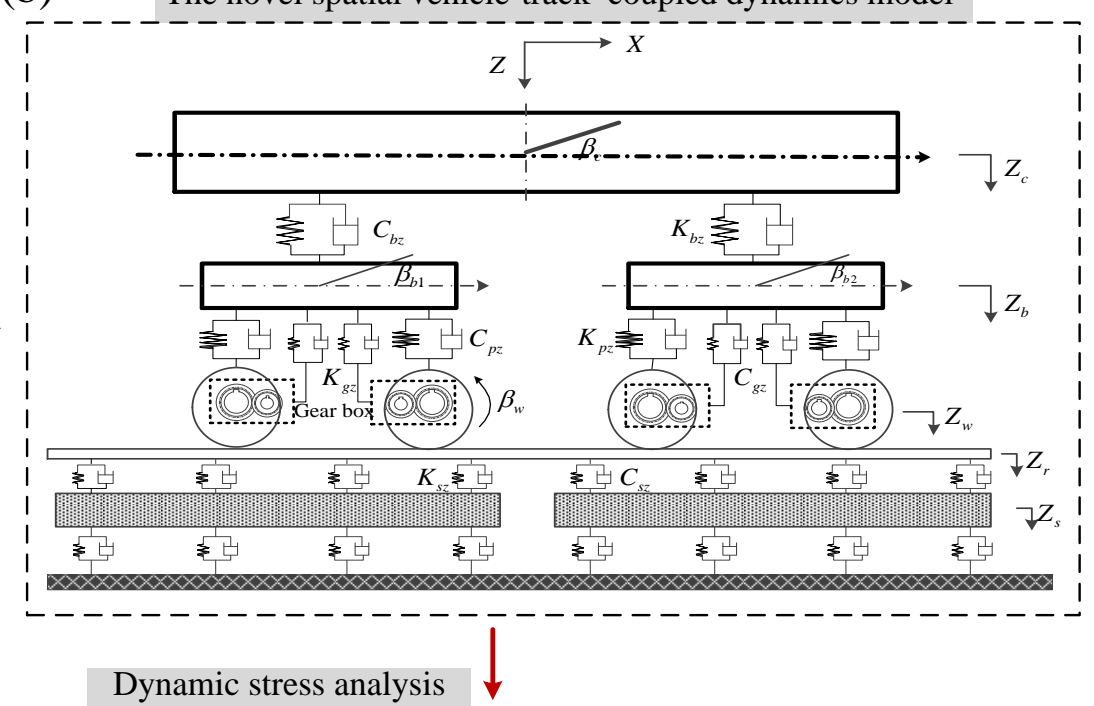

(1). The dynamic forces acted on gearboox housing from bogie frame: lateral and vertical

(2). The dynamic forces acted on gearbox housing from pinion: longitudinal, lateral and vertical;

The dynamic displacement in the center of pinion bearing hole

(3). The displacement constrain: rotate around the axle of wheelset

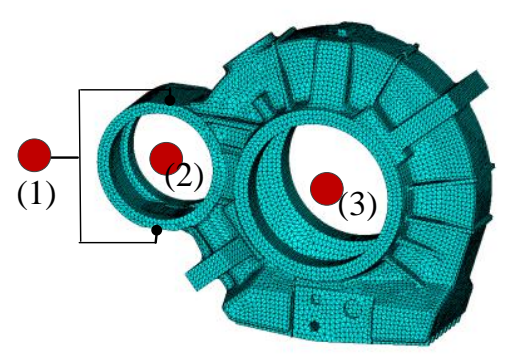

Figure 3 Dynamic stress analysis procedure of the gearbox housing during operation. excitations, (b) three-dimensional vehicle-track coupled dynamics model, (c) boundary of the gearbox housing.

\section{Dynamic simulations and analysis of results}

In this section, the dynamic responses of the whole coupled system are presented based on the simulations excited by track irregularities, traction torque. Experimental field tests are implemented to validate the proposed dynamics model. The vehicle parameters shown in Table 2 are adopted in the simulations. The parameters of the track systems employed in $[30,33]$ are adopted in this investigation. The dynamic characteristics of the gear transmission system in the vehicle-track coupled system are also analysed with various types of wheel defects. It is important to note that the Zhai method is employed to solve the equations of the three-dimensional vehicle-track coupled dynamics model [44].

\begin{tabular}{lll}
\multicolumn{2}{c}{ Table 2 Main parameters of vehicle model } \\
\hline Notation & Specification & Value \\
\hline$M_{c}$ & Car body mass $\left(10^{3} \mathrm{~kg}\right)$ & 33.9 \\
$M_{b}$ & Bogie frame mass $(\mathrm{kg})$ & 2056 \\
$M_{w}$ & Wheelset mass $(\mathrm{kg})$ & 1627 \\
$M_{m}$ & Traction motor mass $(\mathrm{kg})$ & 844 \\
$M_{g}$ & Gear box mass (kg) & 205 \\
$M_{a}$ & Axle box mass (kg) & 66.7 \\
$I_{c x} / I_{c y} / I_{c z}$ & Mass moment of car body about x $/ \mathrm{y} / \mathrm{z}$ axes $\left(10^{3} \mathrm{~kg} / \mathrm{m}^{2}\right)$ & $110 / 1655 / 1562$ \\
$I_{b x} / I_{b y} / I_{b z}$ & Mass moment of bogie frame about x $/ \mathrm{y} / \mathrm{z}$ axes $\left(\mathrm{kg} / \mathrm{m}^{2}\right)$ & $1390 / 2590 / 3800$ \\
$I_{r}$ & Mass moment of rotor about y axes $\left(\mathrm{kg} / \mathrm{m}^{2}\right)$ & 20 \\
$I_{g y}$ & Mass moment of gear box about y axes $\left(\mathrm{kg} / \mathrm{m}^{2}\right)$ & 16
\end{tabular}




\begin{tabular}{lll}
$I_{w x} / I_{w y} / I_{w z}$ & Mass moment of wheelset about x/y/z axes $\left(\mathrm{kg} / \mathrm{m}^{2}\right)$ & $825 / 132 / 830$ \\
$K_{s x} / K_{s y} / K_{s z}$ & Stiffness of secondary suspension along x/y/z $\left(10^{3} \mathrm{~N} / \mathrm{m}\right)$ & $133 / 133 / 203$ \\
$C_{s x} / C_{s y} / C_{s z}$ & Damping of secondary suspension along x/y/z $\left(10^{3} \mathrm{~N} \mathrm{~s} / \mathrm{m}\right)$ & 10.4 \\
$K_{p x} / K_{p y} /$ & Stiffness of primary suspension along x/y $/ \mathrm{z}\left(10^{3} \mathrm{~N} / \mathrm{m}\right)$ & $920 / 920 / 940$ \\
$K_{p z}$ & & \\
$C_{p z}$ & Damping of primary suspension along z $\left(10^{3} \mathrm{~N} \mathrm{~s} / \mathrm{m}\right)$ & 10 \\
$H_{c B}$ & Vertical distance between car body centroid and top of secondary & 0.738 \\
$H_{B t}$ & suspension (m) & \\
$H_{b m}$ & Vertical distance between bogie frame centroid and bottom of secondary & 0.06 \\
$H_{b w}$ & suspension (m) & 0.086 \\
$d_{s}$ & Vertical distance between bogie frame centroid and motor centroid (m) & \\
$d_{s c}$ & Vertical distance between bogie frame centroid and wheelset centerline (m) & 0.06 \\
$d_{w}$ & Semi-lateral distance between secondary suspension (m) & 0.95 \\
$d_{m}$ & Semi-lateral distance between yaw damper (m) & 1.275 \\
$d_{g}$ & Semi-lateral distance between primary suspension (m) & 1.0 \\
$l_{c}$ & Lateral distance between bogie centroid and motor centroid (m) & 0.149 \\
$l_{b}$ & Lateral distance between bogie centroid and gearbox centroid (m) & 0.475 \\
$l_{b m}$ & Semi-longitudinal distance between bogies (m) & 8.6875 \\
$l_{b g}$ & Semi-longitudinal distance between wheelsets in bogie (m) & 1.25 \\
\hline & longitudinal distance between bogie centroid and motor centroid (m) & 0.475 \\
\hline & longitudinal distance between bogie centroid and gearbox centroid (m) & 1.24 \\
\hline
\end{tabular}

\subsection{Experimental tests and model validation}

To validate the model, experimental field tests were carried out along the Beijing-Shanghai highspeed rail line. In addition, the vertical vibration acceleration was collected for the bogie frame and gearbox housing, respectively, with sampling frequencies of 1000 and $5000 \mathrm{~Hz}$.
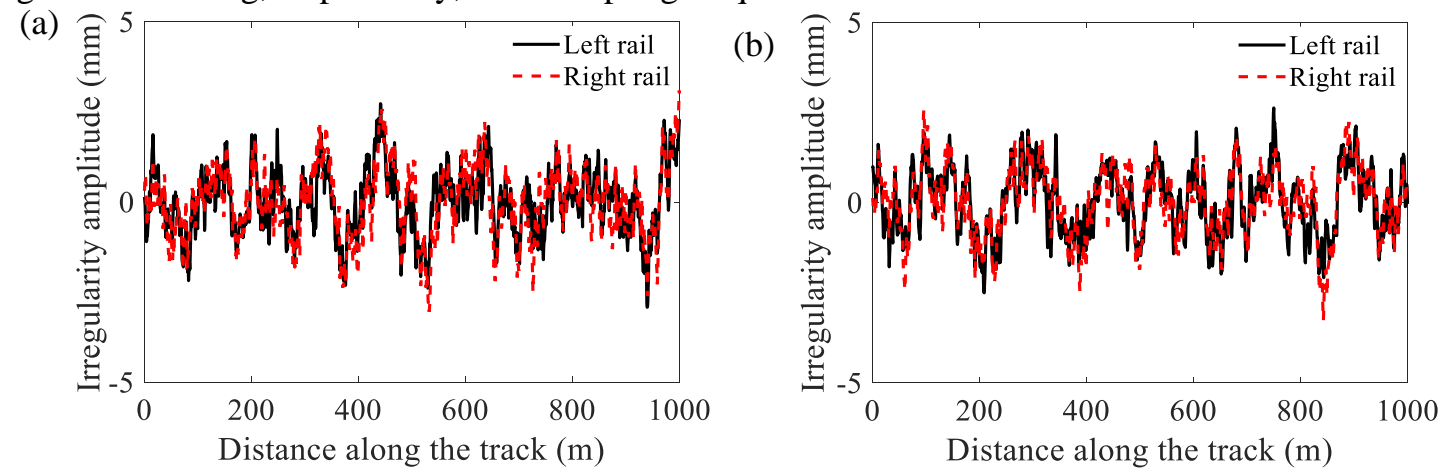

Figure 4 The track irregularities in (a) lateral and (b) vertical direction.

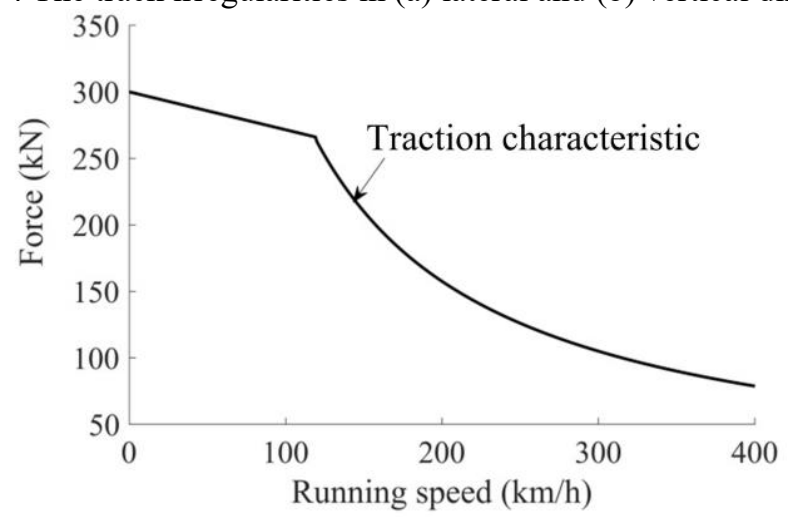

Figure 5 The traction characteristics of the high-speed train

The track irregularities of a high-speed railway line comprising lateral and vertical irregularities is 
adopted in the numerical simulation, as shown in Figure 4. Figure 5 shows the traction characteristics of a typical high-speed train in China, which is the total traction force of this train with respected to different speeds [34]. The real traction torque of the motor can be calculated and assigned to the traction rotor according to the total traction force during simulation. To perform the vehicle running at a constant speed, the equivalent resistant torques are applied to the wheelset. Hence, the proposed model can perform the transmission deliver path from the traction motor to the wheelset.

(a)

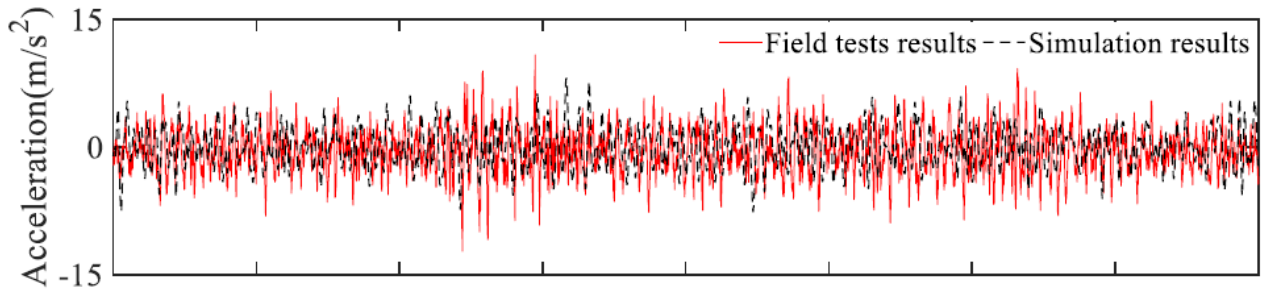

(b)

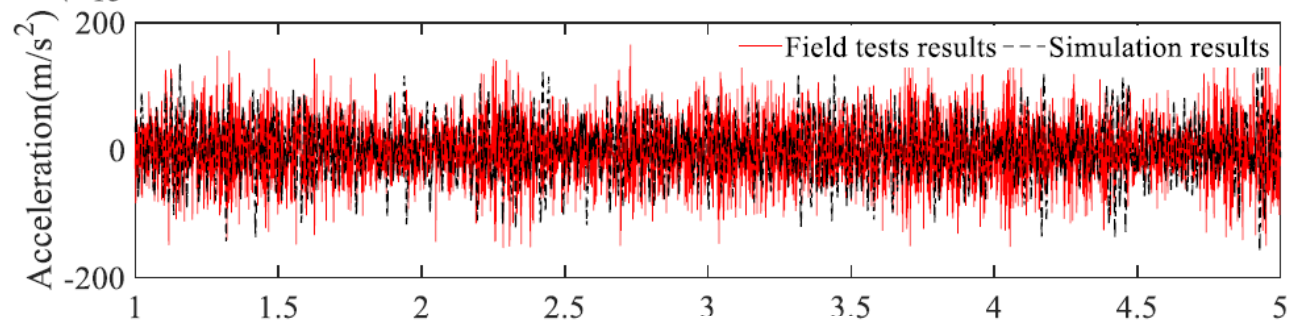

(c)

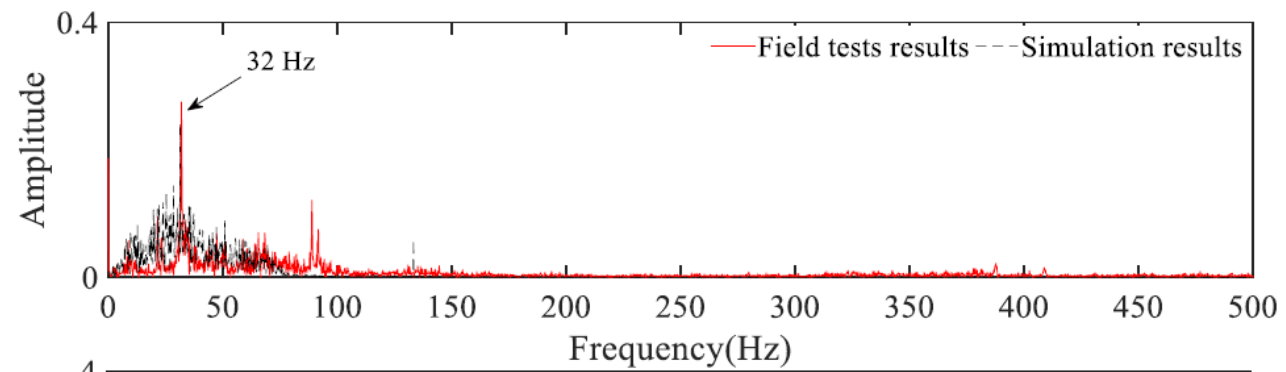

(d)

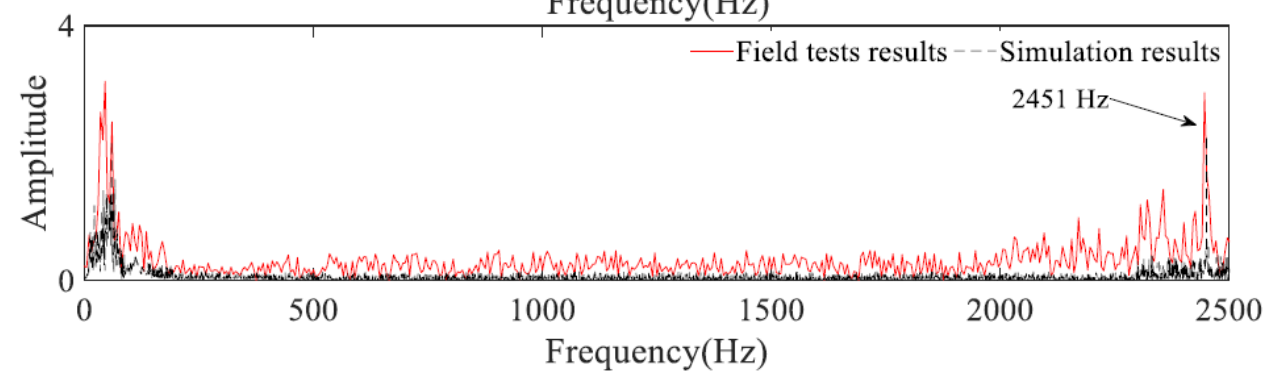

Figure 6 Time domain of: (a) bogie frame and (b) gearbox housing acceleration, and frequency domain of (c) bogie frame and (d) gearbox housing.

Figure 6 demonstrates the results of the bogie frame and gearbox housing obtained through the experimental field tests at $300 \mathrm{~km} / \mathrm{h}$ along a straight track. The corresponding theoretical vibration acceleration calculated via the dynamics model under the same operating conditions is also presented in Figure 6. The maximum amplitudes of the vibration acceleration are approximately 12.2 and $155.4 \mathrm{~m} / \mathrm{s}^{2}$, respectively, for the gearbox housing and the bogie frame. The simulated and experimental results for the bogie frame corroborate one another, both in terms of the characteristic form and amplitude. However, the acceleration of the gearbox housing exhibits some discrepancies between the experimental tests and simulations, as can be observed in Figure 6 (b). The root mean square (RMS) values of the bogie frame vibration accelerations are 2.55 and $2.35 \mathrm{~m} / \mathrm{s}^{2}$ in the field tests and simulations, respectively. Meanwhile, the RMS values of the gearbox housing accelerations are 48.54 and $41.67 \mathrm{~m} / \mathrm{s}^{2}$ for the field tests and simulations, respectively. The details of the comparison between the experimental test and the simulation results are given in Table 3 . Hence, the proposed dynamics model adequately evaluated the vibrations of the vehicle system, albeit with some discrepancies, which may be partly attributed to the neglect of the flexible deformation of the bogie frame, gearbox housing, wheelset, etc. In addition, some nonlinear factors, including the gearbox bearings and their friction, are also neglected here. 
The measured and the simulated responses are also compared in terms of frequency domain, as presented in Figure 6 (c) and (d). The vibration of the bogie frame is mainly comprised of lowfrequency vibrations under $100 \mathrm{~Hz}$, and the results between the experimental tests and numerical simulations are consistent, as can be observed in Figure 6 (c). Regarding the gearbox housing, vibrations mainly under $100 \mathrm{~Hz}$ occurred, whereas vibrations around $2451 \mathrm{~Hz}$ were caused by the gear mesh at $300 \mathrm{~km} / \mathrm{h}$. Both the measured and numerical simulated results of the gearbox demonstrate nearly identical dominant frequencies. In general, the proposed dynamics model suitably reveals the critical vibration characteristics of the gearbox dynamics, confirming the validity of the model for the purpose of this study.

Table 3 The comparison of the results between the simulations and field tests.

\begin{tabular}{|l|c|c|c|c|c|c|}
\hline \multirow{2}{*}{ Component } & \multicolumn{2}{|c|}{ Minimum/maximum amplitude } & \multicolumn{3}{|c|}{ Std value } \\
\cline { 2 - 7 } & Test $\left(\mathrm{m} / \mathrm{s}^{2}\right)$ & $\begin{array}{c}\text { Simulation } \\
\left(\mathrm{m} / \mathrm{s}^{2}\right)\end{array}$ & $\begin{array}{c}\text { Error } \\
(\%)\end{array}$ & $\begin{array}{c}\text { Test } \\
\left(\mathrm{m} / \mathrm{s}^{2}\right)\end{array}$ & $\begin{array}{c}\text { Simulation } \\
\left(\mathrm{m} / \mathrm{s}^{2}\right)\end{array}$ & $\begin{array}{c}\text { Error } \\
(\%)\end{array}$ \\
\hline Bogie frame & $-11.2 / 12.2$ & $-9.9 / 11.3$ & $11.6 / 7.4$ & 2.55 & 2.35 & 7.8 \\
\hline Gearbox housing & $-149.5 / 155.4$ & $-151.3(140.6)$ & $1.2 / 9.5$ & 48.54 & 41.67 & 14.2 \\
\hline
\end{tabular}

\subsection{Dynamic response of the transmission system}

Compared with the traditional vehicle-track coupled dynamics model [33], the main advantages of this developed model are the coupling effects between the transmission and vehicle-track system. The approach in this paper enables the analysis of dynamic effects between the transmission system and the broader vehicle-track coupled dynamic system.

To study the dynamic effect of wheel defects, the vehicle-track dynamic system is excited by (a) only rail irregularities, (b) both track irregularities and 20th order polygonal wear and (c) both track irregularities and wheel flatness. The results of the system are obtained at $300 \mathrm{~km} / \mathrm{h}$ along a straight line, as depicted in Figure 7 and Figure 8. It can be clearly observed that both the lateral and vertical vibrations of the pinion significantly increase due to wheel polygonal wear and flatness. Furthermore, the vertical vibration acceleration of the pinion is greater than that of the lateral vibration acceleration. Owing to the idealized nature of the wheel polygonal wear and flatness, the lateral and vertical vibration accelerations exhibit periodic oscillations at frequencies of 580 and $28.9 \mathrm{~Hz}$, which are associated with the 20th order wheel polygonal wear and flatness at a speed of $300 \mathrm{~km} / \mathrm{h}$.

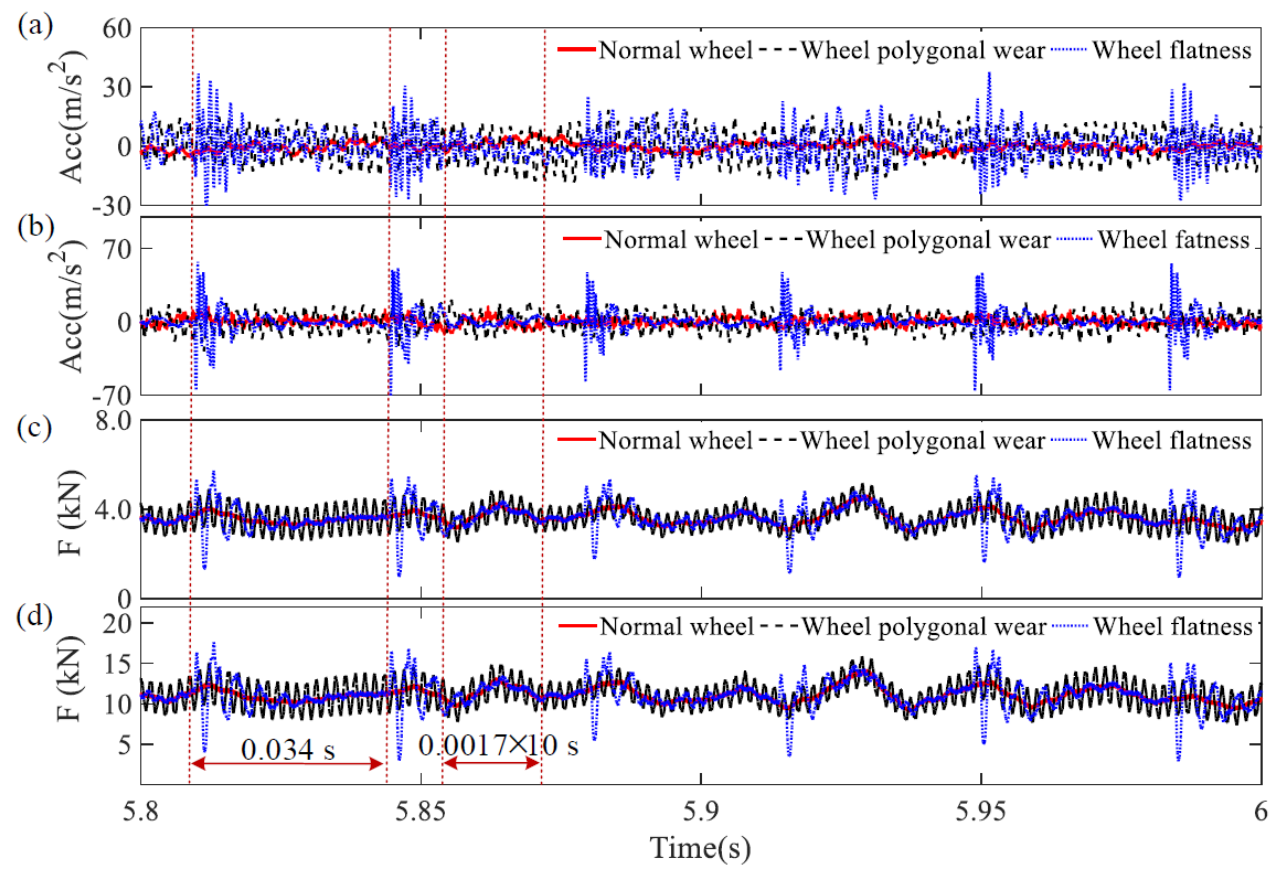

Figure 7 Time histories of (a) the lateral and (b) vertical vibration acceleration of the pinion; (c) the lateral and (d) vertical dynamic forces loaded on the gearbox housing from the pinion.

A similar phenomenon can be found in the lateral and vertical dynamic forces acting on the gearbox housing from the pinion, as displayed in Figure 7 (c) and (d), respectively. The high fluctuation of 
the dynamic force is dominated by wheel polygonal wear and flatness. Hence, both the lateral and vertical dynamic forces between the pinion and gearbox housing experience significant increase due to wheel defects. Although the wheel polygonal wear and flatness have little effect on the lateral suspension forces between the gearbox housing and bogie frame, as shown in Figure 8 (a), they significantly contribute to the fluctuation of the vertical suspension forces, as can be observed in Figure 8 (b).

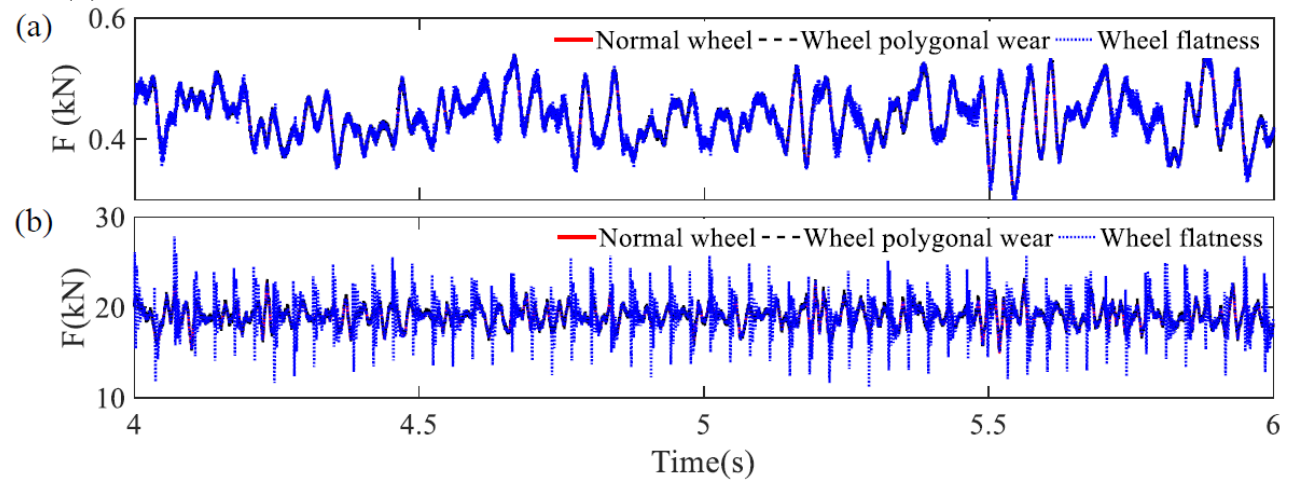

Figure 8 Time histories of (a) the lateral and (b) vertical dynamic forces between the gearbox housing and bogie frame.

\section{Dynamic stress responses of the gearbox during operation}

In this section, the stress characteristics of the gearbox housing is assessed using the obtained dynamic interactions between the gearbox housing and its related components. As shown in Figure 3 , the stress results of the gearbox housing are obtained in the ANSYS environment. The dynamic stress characteristics of the gearbox housing are investigated and discussed below.

\subsection{Dynamic stress field of the gearbox during operation}

Figure 9 presents the dynamic stress responses of the housing at $300 \mathrm{~km} / \mathrm{h}$, including track irregularities and traction torque. It can be observed that the stress is relatively large near the pinion bearing housing and the region between the pinion and gear wheel.
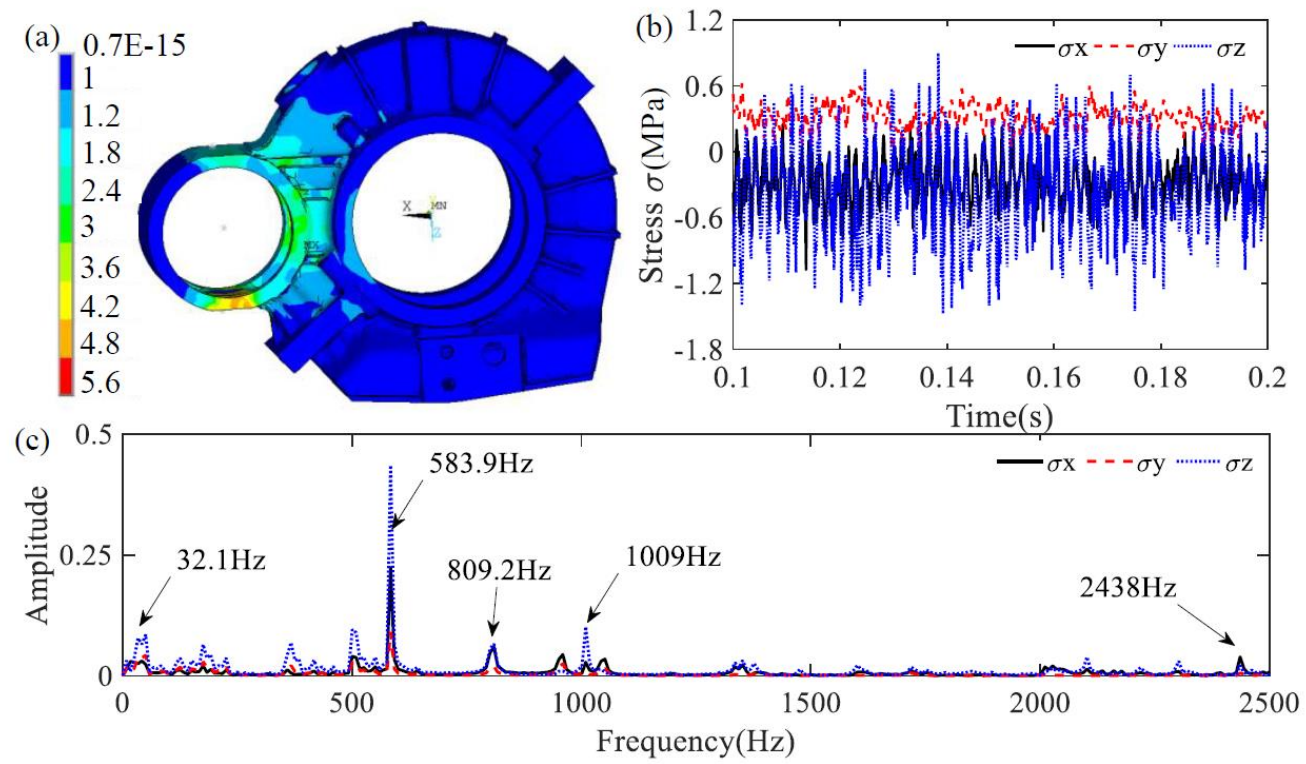

Figure 9 The dynamic responses of the gearbox housing during operation. (a) The von Mises stress distribution, (b) dynamic stress in time domain and (c) frequency domain.

The maximum value of the von Mises stress measures approximately 5.6 MPa during operation, which is far below the intensity standard. Moreover, the dynamic stress time history of the point located on the gearbox housing between the pinion and gear wheel is also depicted in Figure 9 (b). 
The dynamic stresses fluctuate around a nonzero mean value due to the steady-state mesh forces caused by the applied tractive torque. As illustrated in Figure 9 (c), the dynamic stress frequencies mainly consist of the rotational frequency of the wheelset $(32 \mathrm{~Hz})$, the gear mesh frequency $(2438$ $\mathrm{Hz}$ ) and the gearbox modal frequency $(583.9,809.2,1009 \mathrm{~Hz})$, which is discussed later.

\subsection{Effects wheel polygonal wear and flatness}

Figure 10 presents the dynamic response of the gearbox housing excited by polygonal wheel with an amplitude of $0.02 \mathrm{~mm}$, at a speed of $300 \mathrm{~km} / \mathrm{h}$. The dynamic stress of the point near the oil level window (Figure 10 (d)) in three directions is displayed in Figure 10 (a)-(c). Comparing the results with those obtained without wheel polygonal wear, the dynamic stress fluctuates significantly due to the increased dynamic forces acting on the gearbox housing. The stress in the vertical direction is observed to be greater than that of the other two directions, with a maximum value of $20.7 \mathrm{MPa}$. Figure 10 (d) exhibits the frequency results of the dynamic stress of the gearbox housing. A frequency of $580 \mathrm{~Hz}$ for dynamic stress results from the 20th order polygonal wear at $300 \mathrm{~km} / \mathrm{h}$, which is close to the natural frequency of the gearbox housing $(587.1 \mathrm{~Hz})$, as can be observed in Figure 10 (e). Hence, the flexible vibration of the gearbox housing at $580.6 \mathrm{~Hz}$ is excited by the polygonal wheel. Therefore, necessary strategies are needed to avoid the resonance of the gearbox housing when wheel polygonal wear manifests during operation.
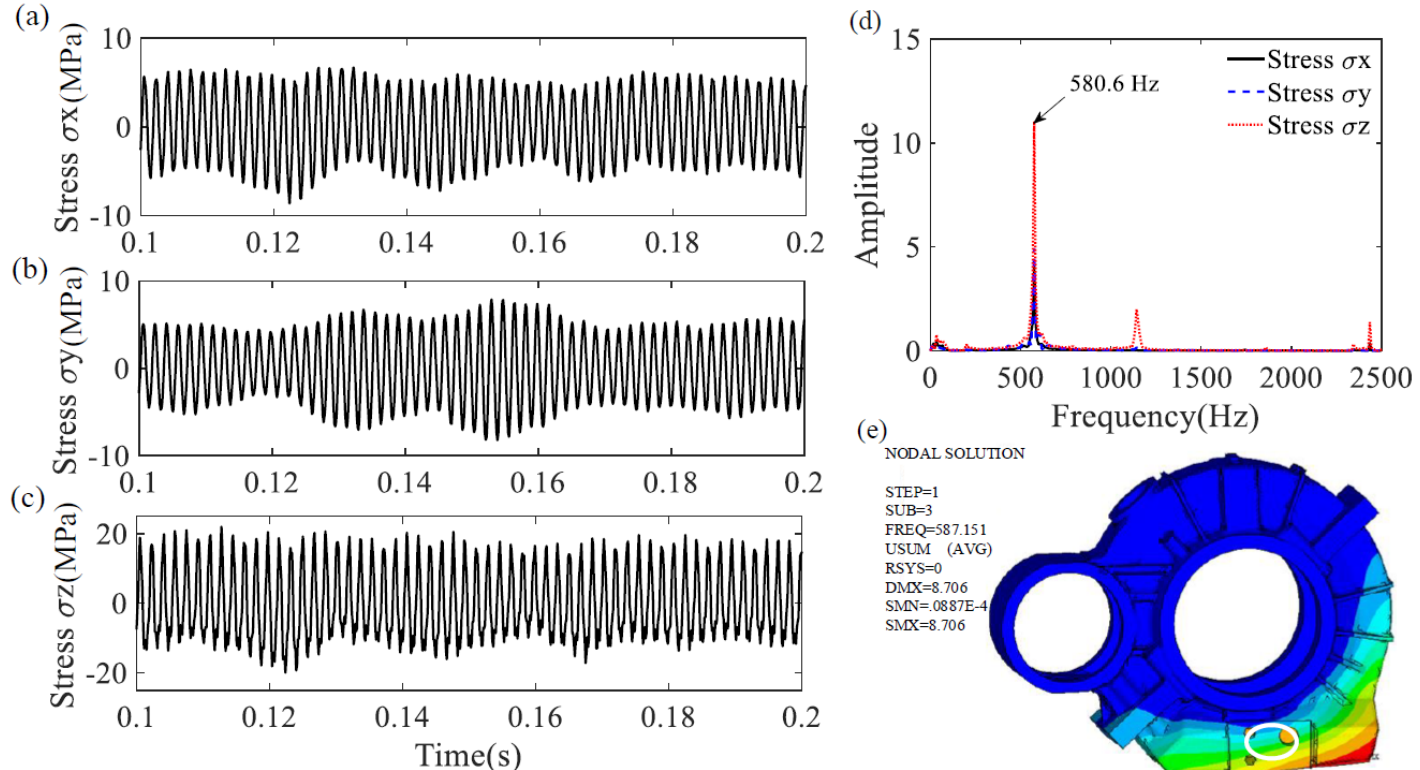

Figure 10 Dynamic stress under the effect of wheel polygonal wear. Time histories of (a) the longitudinal, (b) lateral and (c) vertical dynamic stress; (d) dynamic stress in the frequency domain and (e) the corresponding modal result of the gearbox housing.

Figure 11 gives the dynamic stress of the gearbox housing in the time domain under the effect of wheel flatness with an amplitude of $40 \mathrm{~mm}$ at $300 \mathrm{~km} / \mathrm{h}$. Compared with the results without wheel flatness, the dynamic stress demonstrates a significant influence on the housing's modal vibration characteristics. The maximum amplitude of the dynamic stress reaches a far greater peak of $45 \mathrm{MPa}$ due to wheel flatness. Figure 12 presents the frequency results of the dynamic stress of the gearbox housing. As can be seen in the figure, the frequencies of 583,800 and $998 \mathrm{~Hz}$ are mainly caused by wheel flatness and closely match the natural frequencies of such housing, as illustrated in Figure 12 (b)-(d). 


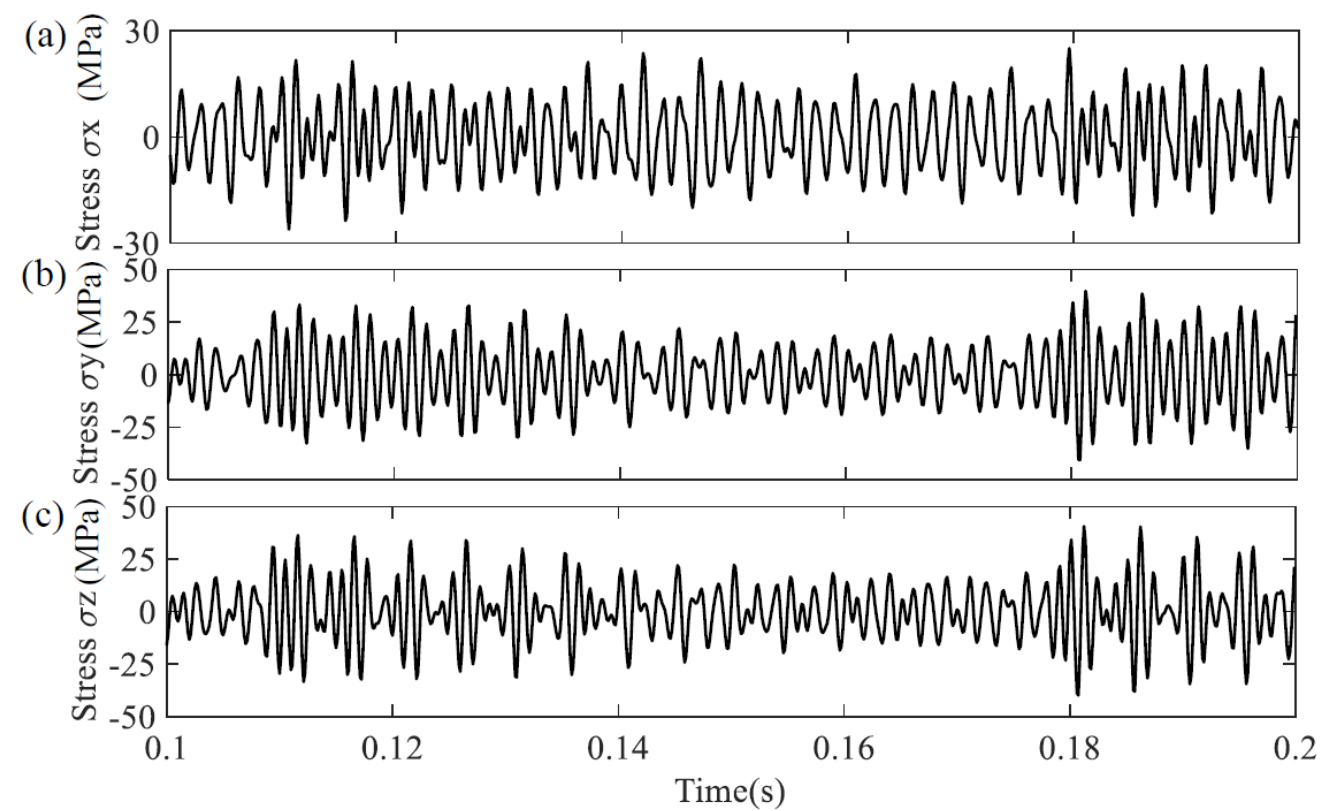

Figure 11 Dynamic stress under the effect of wheel flatness. Time histories of (a) the longitudinal, (b) lateral and (c) vertical dynamic stress.

(a)

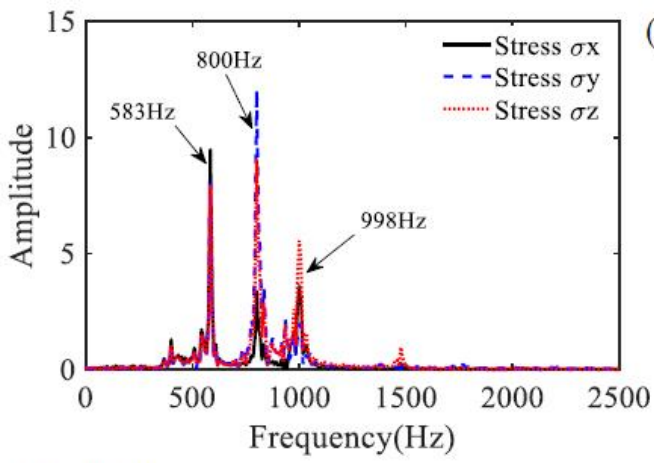

(c) NODAL SOLUTION

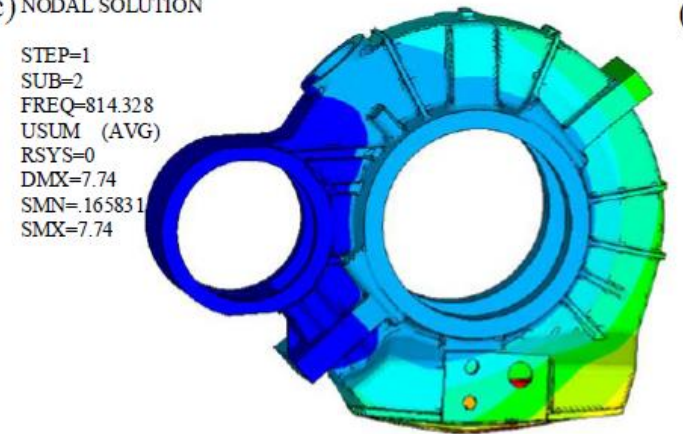

(b) NODAL SOLUTION

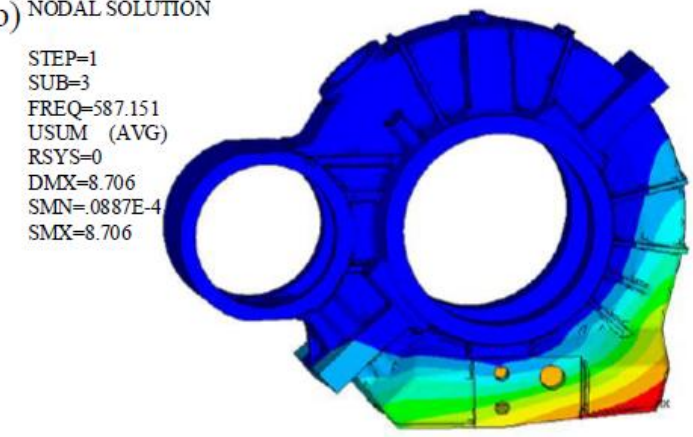

(d) NODAL SOLUTION

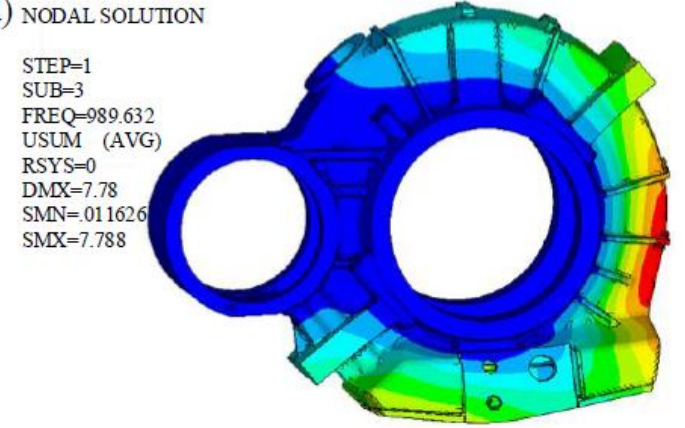

Figure 12 The frequency domain results of the gearbox housing considering wheel flatness. (a) Dynamic stress in the frequency domain and modal results at frequencies of (a) $587 \mathrm{~Hz}$, (b) $814 \mathrm{~Hz}$ and (c) $990 \mathrm{~Hz}$.

\subsection{Influences of the polygonal wear order and wheel flatness length}

Figure 13 illustrates how the order of polygonal wear influences the maxima of the gearbox housing stress at a speed of $300 \mathrm{~km} / \mathrm{h}$. Monitoring point 1 is located near the oil level window, whereas monitoring point 2 is located at the maximum stress point of the gearbox housing. The results are obtained with a polygonal wear amplitude of $0.08 \mathrm{~mm}$ based on a measured wheel profile. The harmonic order of the wheel polygonal wear varies within the range of $0-24$. There is little change in the peak stresses at either monitoring point other than for 20th order wheel polygonal wear. Although various orders of wheel polygonal wear can lead to higher wheel-rail forces, as Figure 13 demonstrates, there is limited effect on the stress of the gearbox housing compared with studies 
without wheel polygonal wear. It indicates that the dynamic stress significantly increases only when the frequency of the dynamic forces induced by polygonal wear coincides with the natural frequency of the gearbox housing.

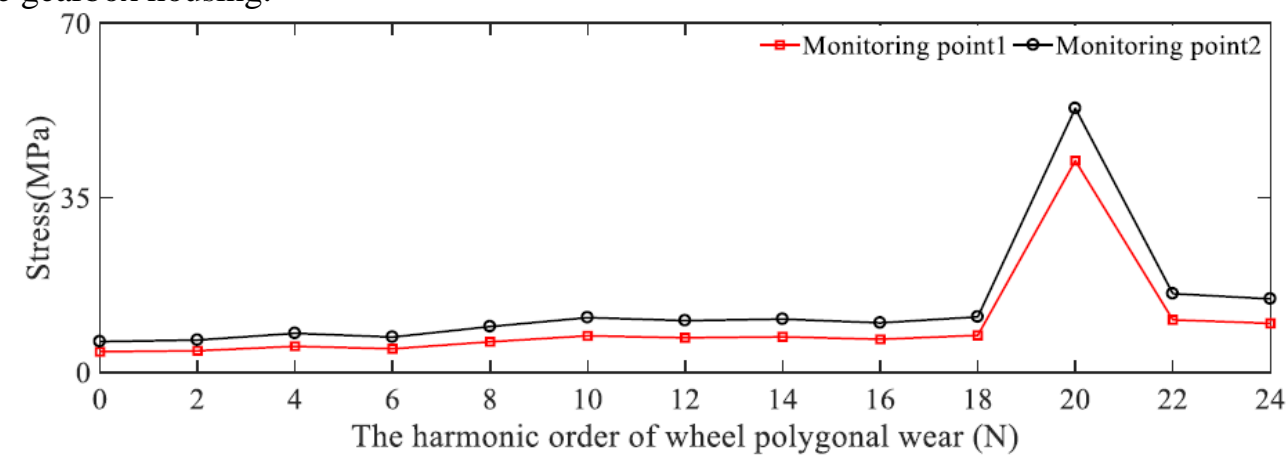

Figure 13 Effect of order of polygonal wear on the gearbox housing (amplitude $=0.08 \mathrm{~mm}$ ).

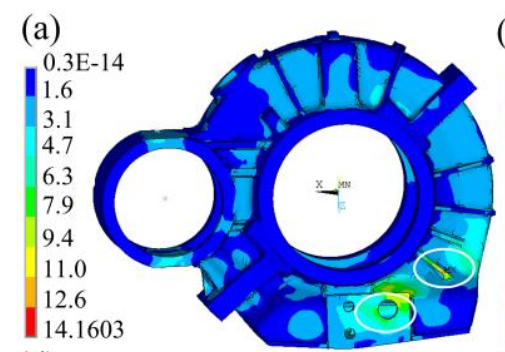

(b)

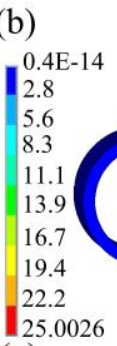

(d) $0.5 \mathrm{E}-14$

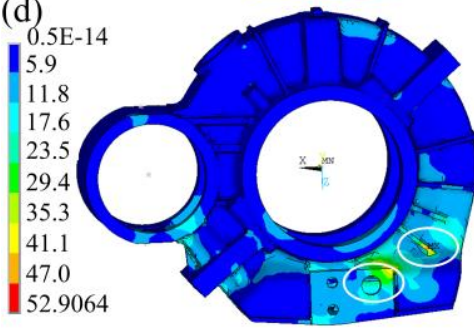

(e)

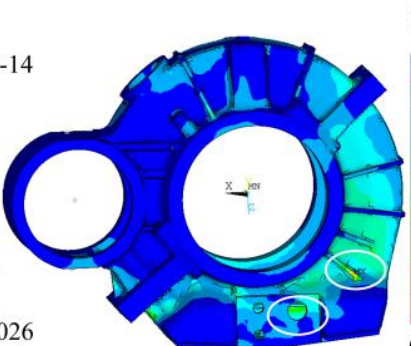

(c)
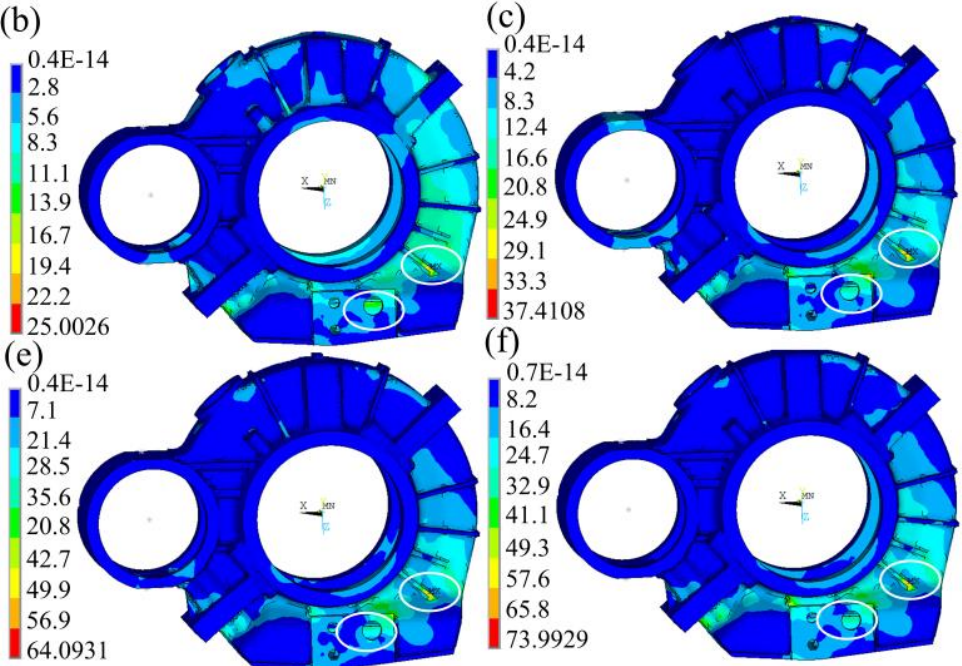

(f)

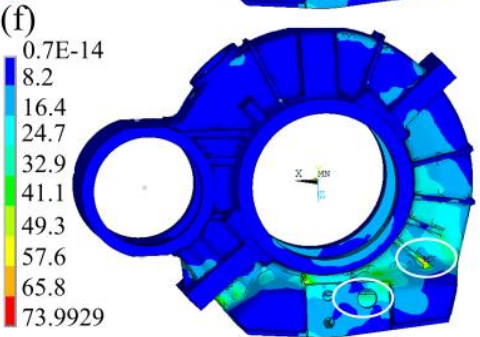

Figure 14 Von Mises stress under wheel polygonal wear with different amplitudes: (a) $0.01 \mathrm{~mm}$, (b) $0.02 \mathrm{~mm}$, (c) $0.04 \mathrm{~mm}$, (d) $0.06 \mathrm{~mm},(e) 0.08 \mathrm{~mm}$ and (f) $0.1 \mathrm{~mm}$.

(a)

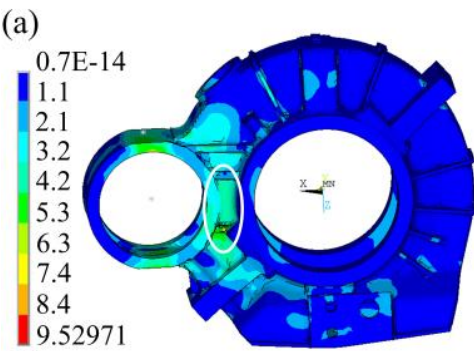

(d)

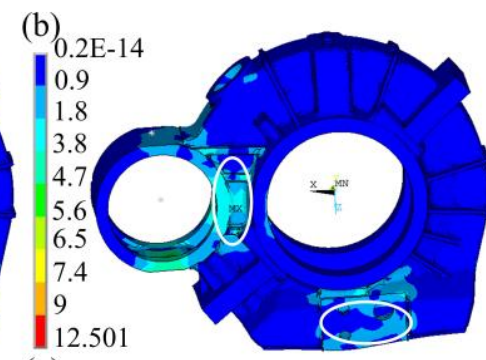

(e)
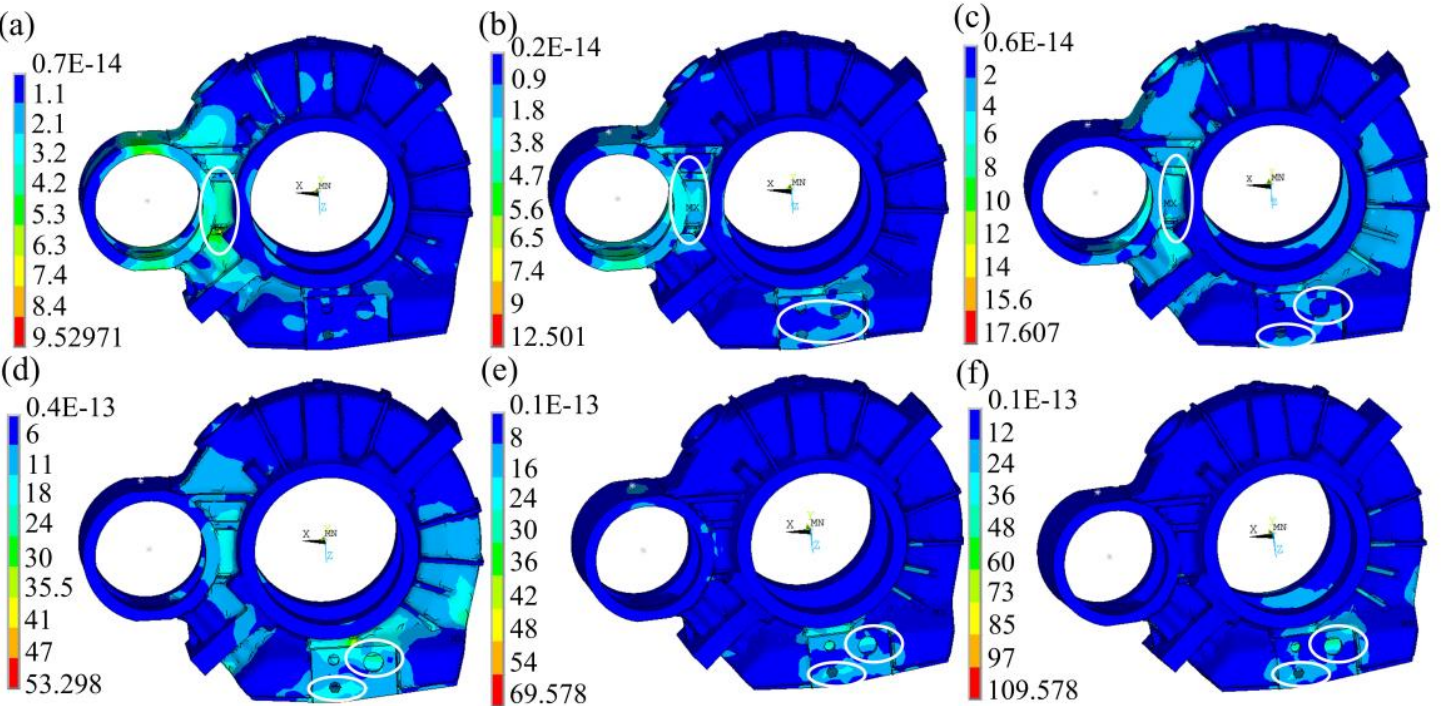

Figure 15 Von Mises stress considering wheel flatness of different lengths: (a) $10 \mathrm{~mm}$, (b) $20 \mathrm{~mm}$,

(c) $30 \mathrm{~mm}$, (d) $40 \mathrm{~mm}$, (e) $50 \mathrm{~mm}$ and (f) $60 \mathrm{~mm}$.

To investigate how the amplitude of 20th order polygonal wear affects the gearbox housing stresses, simulations were carried out with values of wear from 0.01 to $0.1 \mathrm{~mm}$. Figure 14 illustrates the resultant distribution of von Mises stress on the gearbox housing at $300 \mathrm{~km} / \mathrm{h}$. Again, it can be observed that peak stress levels occur in the area around the oil level window, potentially increasing the risk of cracking. When considering the effect of increased amplitude of polygonal wear, the 
maximum value of the von Mises stress increases significantly from 14.2 MPa for a wear amplitude of $0.01 \mathrm{~mm}$ to $74 \mathrm{MPa}$ for a wear amplitude of $0.1 \mathrm{~mm}$. Hence, to reduce the potential for fatiguerelated failures of the gearbox housing, the permissible depth of the common 20th order wheel polygonal wear pattern must be considered.

Figure 15 presents the analytical results regarding wheel flats in terms of the von Mises stress distribution of the gearbox housing with varying flat lengths at a speed of $300 \mathrm{~km} / \mathrm{h}$. Both wheels of the wheelset have the same flat length, with zero phase difference between flats. When the length of wheel flat under $40 \mathrm{~mm}$, the stress is greatest in the area between the pinion and gear wheel hole. However, the stress is greatest in the area around the oil level window and the bottom of the gearbox housing when the wheel flat length over $40 \mathrm{~mm}$. Furthermore, the maximum amplitude of the stress field increases from 9.5 MPa for a flat length of $10 \mathrm{~mm}$ to $110 \mathrm{MPa}$ with a $60-\mathrm{mm}$ flat. The influence of wheel flats on stress levels is lower for lengths below $30 \mathrm{~mm}$; however, stress increases rapidly beyond this value. Hence, wheel flatness likely poses a significant risk to the onset of fatigue-related failures of the gearbox housing, particularly around the bottom of the casing and the oil level window aperture.

\section{Conclusions}

A three-dimensional vehicle-track coupled dynamics model, including the transmission system, has been developed and validated using field test data. The model comprises the lateral, vertical and pitch motions of the gearbox and has demonstrated accurate reproduction of the gearbox vibrations during the operational running conditions of a high-speed train.

The coupling effects within the gear transmission system are considered in detail, including the excitation from internal (gear meshing) and external (traction motor and wheel-rail) vibrations. Based on the coupling analysis, combined with the operational vibration environment, the dynamic stresses within the gearbox housing have been analysed using the FEM.

The vibration characteristics of the gearbox have been studied in depth regarding wheel polygonal wear and flatness. The high-impact nature of the resulting wheel-rail force, combined with excitations due to gear meshing forces acting on the gearbox housing via the drive pinion and wheelset, significantly influences the gearbox housing stresses in both the lateral and vertical directions.

The results of our analyses indicate the stresses in the region of the pinion bearing hole are higher than that of the other areas of the gearbox housing during normal operating conditions. However, the stresses in the vicinity of the oil window are found to be the greatest. Based on our results, this stress is caused by the resonance of the housing associated with 20th order polygonal wear. When the polygonal wear amplitudes increase from 0.01 to $0.1 \mathrm{~mm}$, the maximum von Mises stress increases from 14.1 to approximately $74 \mathrm{MPa}$. Such stress levels likely lead to fatigue cracking issues in the vicinity of the oil level window. Hence, it is important to identify and set limit values for the amplitude of 20th order polygonal wear.

When considering wheel flats, the maximum amplitude of the gearbox housing stresses increases from 9.5 to $110 \mathrm{MPa}$ as a result of the flat length increasing from 10 to $60 \mathrm{~mm}$, respectively. The influence of wheel flats on stress levels is lower for lengths below $40 \mathrm{~mm}$; however, the stress levels increase rapidly for flat lengths ranging from 40 to $60 \mathrm{~mm}$. In the frequency domain, the related frequencies of dynamic stress are found at 583, 800 and $998 \mathrm{~Hz}$, all of which are aligned with the natural frequencies of the gearbox housing. The stress in the vicinity of the oil window and the bottom section of the gearbox housing is relatively high, which, like the polygonal wear problem, is likely to contribute to cracks in the housing. Therefore, it can be concluded that maintenance practices of wheel profiles must detect and limit wheel defects to keep the gearbox housing working safely in a low-stress state.

The gearbox housing is mounted on the wheelset, which effects the vibration of such system. The flexible deformation of the wheelset could affect the dynamic responses of the gearbox housing. However, the proposed dynamics model considers the vehicle system as a rigid body, which could be improved in the future. 


\section{Acknowledgment}

The first author thanks the support of the China Scholarship Council.

\section{Funding}

The author(s) is grateful for the financial support provided by the National Key Research and Development Program of China (Grant No 2016YFB1200401-102A and 102B), the National Natural Science Foundation of China (Grant No. 51475391).

\section{References}

1 Huang GH, Zhou N and Zhang WH. Effect of internal dynamic excitation of the traction system on the dynamic behavior of a high-speed train. Proc IMechE, Part F: J Rail and Rapid Transit 2016; 230(8): 1899-1907.

2 Wang ZW, Mei GM, Zhang WH, et al. Effects of polygonal wear of wheels on the dynamic performance of the gearbox housing of a high-speed train. Proc IMechE, Part F: J Rail and Rapid Transit 2018; 232(6): 1852-1863.

3 Nielsen JCO and Johansson A. Out-of-round railway wheels-a literature survey. Proc IMechE, Part F: J Rail and Rapid Transit 2000; 214(2): 79-91.

4 Barke DW and Chiu WK. A review of the effects of out-of-round wheels on track and vehicle components. Proc IMechE, Part F: J Rail and Rapid Transit 2005; 219(3): 151-175.

5 Henao H, Kia SH and Capolino GA. Torsional-vibration assessment and gear-fault diagnosis in railway traction system. IEEE Trans Ind Electron 2011; 58(5): 1707-1717.

6 Iwnicki S. Handbook of railway vehicle dynamics. Boca Raton, FL: CRC Press, 2006.

$7 \mathrm{Wu} \mathrm{XW}$, Rakheja S, Ahmed AKW, et al. Influence of a flexible wheelset on the dynamic responses of a high speed railway car due to a wheel flat. Proc IMechE, Part F: J Rail and Rapid Transit 2017; 232(4): 1033-1048.

$8 \mathrm{Wu}$ TX and Thompson DJ. The effects of track nonlinearity on wheel/rail impact. Proc MechE, Part F: J Rail and Rapid Transit 2004; 218(1): 1-15.

9 Brommundt E. A simple mechanism for the polygonalization of railway wheels by wear. Mech Res Commun 1997; 24(4): 435-442.

10 Morys B. Enlargement of out-of-round wheel profiles on high speed train. J Sound Vib 1999; 227(5): 965-978.

$11 \mathrm{Wu}$ XW, Chi MR, Wu PB. Influence of polygonal wear of railway wheels on the wheel set axle stress. Veh Syst Dyn 2015; 53(11): 1535-15454.

12 Dukkipati RV and Dong R. Impact loads due to wheel flats and shells. Veh Syst Dyn 1999; 31(1): $1-22$.

13 Hou K, Kalousek J and Dong R. A dynamic model for an asymmetrical vehicle/track system. J Sound Vib 2003; 267(3): 591-604.

14 Newton SG and Clark RA. An investigation into the dynamic effects on the track of wheel flats on railway vehicles. J Mech Eng Sci 1979; 21(4): 287-297.

15 Knothe K and Grassie SL. Modelling of railway track and vehicle/track interaction at high frequencies. Veh Syst Dyn 1993; 22(3): 209-262.

16 Sun YQ and Dhanasekar M. A dynamic model for the vertical interaction of the rail track and wagon system. Int J Solids Struct 2002; 39: 1337-1359.

17 Baeza L, Fayos J, Roda A, et al. High frequency railway vehicle-track dynamics through flexible rotating wheelsets. Veh Syst Dyn 2008; 46(7): 647-659.

18 Baeza L, Vila P, Xie G, et al. Prediction of rail corrugation using a rotating flexible wheelset coupled with a flexible track model and a non-Hertzian/non-steady contact model. J Sound Vib 2011; 330(18-19): 4493-4507.

19 Jin X,Wu L, Fang J, et al. An investigation into the mechanism of the polygonal wear of metro train wheels and its effect on the dynamic behaviour of a wheel/rail system. Veh Syst Dyn 2012;50(12):1817-1834. 
20 Johansson A, Andersson C. Out-of-round railway wheels - a study of wheel polygonalization through simulation of three-dimensional wheel-rail interaction and wear. Veh Syst Dyn 2005;43(8):539-559.

21 Kaper HP.Wheel corrugation on Netherlands railways (NS): origin and effects of "polygonization" in particular. J Sound Vib 1988;120(2):267-274.

22 Zhang J, Han GX, Xiao XB, et al. Influence of wheel polygonal wear on interior noise of highspeed trains. J Zhejiang Univ Sci A 2014;15(12):1002-1018.

23 Johansson A and Nielsen JCO. Out-of-round railway wheels-wheel-rail contact forces and track response derived from field tests and numerical simulations. Proc IMechE, Part F: J Rail and Rapid Transit 2003; 217(2): 135-146.

24 Wang ZW, Cheng Y, Mei GM, et al. Torsional vibration analysis of the gear transmission system of high-speed trains with wheel defects. Proc IMechE, Part F: J Rail and Rapid Transit 2019 DOI: $10.1177 / 0954409719833791$.

$25 \mathrm{Gu}$ X, Velex P. On the dynamic simulation of eccentricity errors in planetary gears. Mech. Mach. Theory 2013; 61: 210-229.

26 Velex P, Sainaot P. An analytical study of tooth fraction excitations in errorless spur and helical gears. Mech. Mach. Theory 2002; 37(7): 641-658.

27 Brethee KF, Zhen D, Gu FS, et al. Helical gear wear monitoring: Modelling and experimental validation. Mech. Mach. Theory 2017; 117: 210-229.

28 Park D, Kahraman A. A surface wear model for hypoid gear pairs. Wear 2009; 267 (9-10): 15951604.

29 Chen ZG, Zhai WM and Wang KY. Locomotive dynamic performance under traction/braking conditions considering effect of gear transmissions. Veh Syst Dyn 2018; 56(7): 1-21.

30 Wang ZW, Zhang WH, Yin ZH, et al. Effect of vehicle vibration environment of high speed train on dynamic performance of axle box bearing. Veh Syst Dyn 2019; 57(4): 543-563.

31 Wang ZW, Cheng Y, Allen P, et al. Analysis of vibration and temperature on the axle box bearing of a high-speed train. Vehicle System Dynamics, 2019, DOI: 10.1080/00423114.2019.1645340.

32 Wang ZW, Allen P, Mei GM, et al. Influence of wheel-polygonal wear on the dynamic forces within the axle-box bearing of a high-speed train. Vehicle System Dynamics, 2019, DOI: 10.1080/00423114.2019.1626013.

33 Zhai WM. Vehicle-track coupling dynamics. Beijing, China: Science Publishing House; 2007. p. $12-132$.

34 Wang ZW, Mei GM, Xiong Q, et al. Motor car-track spatial coupled dynamics model of a highspeed train with traction transmission systems. Mechanism and Machine Theory, 2019, 137: 386403.

35 Lin L, Xiao XB, Xiong, JY, et al. A 3D model for coupling dynamics analysis of high-speed train/track system. J. Zhejiang Univ. Sci. A, Appl. Phys. Eng 2014; 15 (12): 964-983.

36 Timoshenko, S.: Vibration Problems in Engineering, 4th edn. Wiley, USA (1974).

37 Zhai WM. Vehicle-track coupled dynamics. 4th ed. Beijing: Science Press; 2015.

38 Chen G, Zhai WM. A new wheel/rail spatially dynamic coupling model and its verification, Veh Syst Dyn. 2004;41(4):301-322.

39 Shen ZY, Hedrick JK, Elkins JA. A comparison of alternative creep force models for rail vehicledynamic analysis. Veh Syst Dyn 1983;12(1-3):79-83.

40 Kalker JJ. Three-dimensional elastic bodies in rolling contact. Vol. 2. Dordrecht: Springer Science \& Business Media; 1990.

41 Dong R. Vertical dynamics of railway vehicle-track system. Doctoral Dissertation, Concordia University, Montreal, Canada.

42 Guo ZY, You SH, Wan XP, et al., A FEM-based direct method for material reconstruction inverse problem in soft tissue elastography. Comput Struct 2010; 88: 1459-1468.

43 Zienkiewicz OC, Taylor RL. The finite element method for solid and structural mechanics, 6th ed., vol. xv. Oxford: Elsevier Butterworth-Heinemann; 2005.

44 Zhai,W.M., 1996. Two simple fast integration methods for large-scale dynamic problems in engineering. Int. J. Numer. Methods Eng. 39 (24), 4199-4214. 